\title{
Competition policy and cartel size
}

\author{
Citation for published version (APA):
}

Bos, A. M., \& Harrington Jr., J. E. (2013). Competition policy and cartel size. Maastricht University, Graduate School of Business and Economics. GSBE Research Memoranda No. 027 https://doi.org/10.26481/umagsb.2013027

Document status and date:

Published: 01/01/2013

DOI:

10.26481/umagsb.2013027

Document Version:

Publisher's PDF, also known as Version of record

\section{Please check the document version of this publication:}

- A submitted manuscript is the version of the article upon submission and before peer-review. There can be important differences between the submitted version and the official published version of record.

People interested in the research are advised to contact the author for the final version of the publication, or visit the DOI to the publisher's website.

- The final author version and the galley proof are versions of the publication after peer review.

- The final published version features the final layout of the paper including the volume, issue and page numbers.

Link to publication

\footnotetext{
General rights rights.

- You may freely distribute the URL identifying the publication in the public portal. please follow below link for the End User Agreement:

www.umlib.nl/taverne-license

Take down policy

If you believe that this document breaches copyright please contact us at:

repository@maastrichtuniversity.nl

providing details and we will investigate your claim.
}

Copyright and moral rights for the publications made accessible in the public portal are retained by the authors and/or other copyright owners and it is a condition of accessing publications that users recognise and abide by the legal requirements associated with these

- Users may download and print one copy of any publication from the public portal for the purpose of private study or research.

- You may not further distribute the material or use it for any profit-making activity or commercial gain

If the publication is distributed under the terms of Article $25 \mathrm{fa}$ of the Dutch Copyright Act, indicated by the "Taverne" license above, 


\section{Maastricht University}

I wan Bos,

Joseph E. Harrington J r.

Competition policy and cartel size

$\mathrm{RM} / 13 / 027$

\section{GSBE}

Maastricht University School of Business and Economics

Graduate School of Business and Economics

P.O Box 616

NL-6200 MD Maastricht

The Netherlands 


\title{
Competition Policy and Cartel Size
}

\author{
Iwan Bos* Joseph E. Harrington, Jr. ${ }^{\dagger}$ \\ 24 May 2013 \\ JEL Classification: L1, L4 \\ Key Words: Competition Policy, Antitrust Enforcement, \\ Cartel Size, Cartel Stability
}

\begin{abstract}
This paper examines endogenous cartel formation in the presence of a competition authority. Competition policy makes the most inclusive stable cartels less inclusive. In particular, small firms that might have been cartel members in the absence of a competition authority are no longer members. Regarding the least inclusive stable cartels, competition policy can either increase or decrease their inclusiveness. Highly inelastic market demand is sufficient for the presence of a competition authority to cause the least inclusive stable cartels to increase in size.
\end{abstract}

\section{Introduction}

Research has extensively explored how competition policy affects whether collusion is stable and, when it is stable, the price set by cartel members and the cartel's duration. For example, there is a large and growing literature that examines the impact of corporate leniency programs on whether a cartel forms and what price it sets if it does form. ${ }^{1}$ All that analysis, however, has made two restrictive assumptions about the cartel's composition. First, that the cartel is all-inclusive. Second, that the inclusiveness of the cartel is fixed with regards to competition policy. Practice runs contrary to the first assumption in that many cartels comprise some, but not all, firms in a market ${ }^{2}$ and, with regards to the second assumption, it is natural to expect that a tougher competition policy could influence which firms choose to join a cartel and how inclusive a cartel must be for the cartel to be stable.

The objective of this paper is to explore the impact of competition policy on a cartel's size and composition. In earlier work (Bos and Harrington, 2010), the set of

\footnotetext{
${ }^{*}$ Maastricht University, School of Business and Economics, Department of Organization \& Strategy. Address: Tongersestraat 53, Maastricht, 6211 LM, The Netherlands. E-mail: i.bos@maastrichtuniversity.nl.

${ }^{\dagger}$ University of Pennsylvania, The Wharton School, Department of Business Economics \& Public Policy. Address: 3620 Locust Walk, Philadelphia, PA 19102. E-mail: harrij@wharton.upenn.edu.

${ }^{1}$ For references, see Spagnolo (2008) and Harrington and Chang (2012).

${ }^{2}$ Examples are in Harrington (2006) and Bos and Harrington (2010) and references cited therein.
} 
stable cartels was characterized but in the absence of antitrust enforcement. In this paper, that model is amended to allow for a competition authority that can detect and convict cartels and, as a consequence, impose financial penalties and cause the cartel to shutdown. We also allow for a corporate leniency program so that a cartel member can receive a reduced penalty in exchange for cooperating with the authorities.

Our main findings are, for the most part, based on assessing the impact of introducing a competition authority; that is, comparing the set of stable cartels with antitrust enforcement with the set of stable cartels without antitrust enforcement. First, we find that competition policy results in the most inclusive stable cartel being less inclusive. In particular, small firms are no longer cartel members when there are competition laws and an authority to enforce them. Second, more severe penalties cause the size of the most profitable cartel to shrink which again suggests that competition policy is making for less inclusive cartels. Third, antitrust enforcement has an ambiguous effect on the size of the least inclusive stable cartels. If market demand is highly inelastic then the least inclusive stable cartels encompass more firms, but there are other market conditions such that the least inclusive stable cartels involve fewer firms. Combining these results, we find that either antitrust enforcement reduces the range of sizes of stable cartels - as it increases the size of the smallest cartels and decreases the size of the largest cartels - or it shifts the range of stable cartels down - making the most and least inclusive cartels less encompassing.

In the next section, the model is introduced. Section 3 establishes equilibrium cartel behavior, while Section 4 provides the conditions for a cartel to be stable. The main results of the paper are in Section 5 which characterizes the impact of antitrust enforcement on the set of stable cartels. Section 6 concludes.

\section{Model}

To explore the impact of competition policy on the inclusiveness of cartels, the capacity-constrained price-setting repeated game in Bos and Harrington (2010) is modified to allow for a cartel to be convicted and penalized. Consider an industry with $n \geq 3$ firms producing a homogeneous good at common marginal cost $c \geq 0$. $^{3}$ Let $N \equiv\{1, \ldots, n\}$ denote the set of firms. Firm $i$ has a fixed production capacity $k_{i}$ and, without loss of generality, assume $k_{1} \geq k_{2} \geq \cdots \geq k_{n}$. Firms have a common discount factor $\delta \in(0,1)$. The setting is one of perfect monitoring so, in any period, all past prices are common knowledge.

Market demand is given by $D(p)$ which is a twice continuously differentiable and decreasing function of price. Moreover, $D(c)>0$ and monopoly profit, $(p-c) D(p)$, is strictly concave. The monopoly price $p^{m}$ is defined by: $D\left(p^{m}\right)+\left(p^{m}-c\right) D^{\prime}\left(p^{m}\right)=$ 0 . In each period, firms simultaneously choose prices from $\{0, \varepsilon, \ldots, c-\varepsilon, c, c+\varepsilon, \ldots\}$ and produce to meet demand up to capacity. Results will be derived for $\varepsilon>0$ and

\footnotetext{
${ }^{3}$ Given that we are interested in exploring the inclusivity of cartels, it is necessary to assume there are at least three firms. Furthermore, assumptions made below on capacity imply there must be at least three firms; for an elaboration, see Bos and Harrington (2010).
} 
sufficiently small. ${ }^{4}$ Demand of firm $i$ is denoted $D_{i}\left(p_{i}, p_{-i}\right)$, which depends on its own price $p_{i}$ and the vector of rivals' prices, $p_{-i}$. As in Bos and Harrington (2010), three fairly general assumptions are made on firm demand and capacities. In stating these assumptions, let $\Phi(p) \equiv\left\{j: p_{j}=p\right\}$ denote the set of firms that price at $p$ and define $p_{-i}^{\min } \equiv \min \left\{p_{1}, \ldots, p_{i-1}, p_{i+1}, \ldots, p_{n}\right\}$.

A1 $\lim _{\eta \rightarrow 0^{+}} D_{i}\left(p_{-i}^{\min }+\eta, p_{-i}\right)=\max \left\{D\left(p_{-i}^{\min }\right)-\sum_{j \in \Phi\left(p_{-i}^{\min }\right)} k_{j}, 0\right\}$.

$\mathbf{A 2}$ If $0<\sum_{i \in \Phi(p)} D_{i}\left(p_{i}, p_{-i}\right)<\sum_{i \in \Phi(p)} k_{i}$ then $0<D_{i}\left(p_{i}, p_{-i}\right)<k_{i}, \forall i \in \Phi(p)$.

A3 $k_{i}<D\left(p^{m}\right)$ and $\sum_{j \neq i} k_{j} \geq D(c), \forall i \in N$.

A1 holds for any well-behaved residual demand function, while A2 imposes some symmetry across firms. The first part of A3 imposes an upper bound on firm size. It has the implication that, for prices not exceeding the monopoly price, a firm that charges a price below all of its rivals is capacity-constrained. The second part of A3 states that any $n-1$ firms have sufficient production capacity to meet competitive demand. This assumption ensures that the one-shot game has two symmetric Nash equilibria with prices of $c$ and $c+\varepsilon$. Thus, for sufficiently small $\varepsilon$, static Nash equilibrium profit is approximately zero.

Firms can potentially enhance their profits through the formation of a price-fixing cartel. Consider a cartel $\Gamma \subseteq N$ with common cartel price $p>c+\varepsilon$. If $\Gamma \subset N$, then the cartel faces competition from at least one outsider. ${ }^{5}$ As proven in Lemma 2 in Bos and Harrington (2010), non-colluding firms optimally set their prices slightly below the cartel price and produce up to capacity. Residual cartel demand is then given by $D(p)-\left(K-K_{\Gamma}\right)$, where $K=\sum_{i \in N} k_{i}$ and $K_{\Gamma}=\sum_{i \in \Gamma} k_{i}$ denote, respectively, industry and cartel capacity. Clearly, collusion is beneficial only when the cartel faces positive demand, which requires $D(p)-\left(K-K_{\Gamma}\right)>0$ or $K_{\Gamma}>K-D(p)$. Thus, a necessary condition for a cartel to be successful is that it controls a sufficiently large part of industry capacity. Under the assumption that cartel profit is allocated in proportion to capacity, profit of firm $i \in \Gamma$ is: ${ }^{6}$

$$
(p-c)\left[D(p)-\left(K-K_{\Gamma}\right)\right]\left(\frac{k_{i}}{K_{\Gamma}}\right)
$$

Firms that take part in a cartel become subject to antitrust enforcement. In each period in which at least one firm sets the collusive price, the antitrust authority discovers cartel $\Gamma$ with probability $\rho(\Gamma) \in[0,1]$. Thus, $\rho(\cdot)$ maps from the set of subsets of $N$ with at least two members into $[0,1]$. The absence of antitrust enforcement is when $\rho(\cdot)=0$. In the event of an investigation, conviction occurs for sure and results in the immediate and permanent break-down of the cartel; hence, firms return to a

\footnotetext{
${ }^{4}$ While there is no explicit reference made to $\varepsilon$ in the results of this paper, we draw upon results in Bos and Harrington (2010) which presume $\varepsilon$ is sufficiently small.

${ }^{5} \subset$ refers to strict set inclusion so that $\Gamma^{\prime} \subset \Gamma^{\prime \prime}$ means $\Gamma^{\prime}$ is a strict subset of $\Gamma^{\prime \prime}$.

${ }^{6} \mathrm{~A}$ motivation and extensive discussion of this assumption is provided in Bos and Harrington (2010).
} 
static Nash equilibrium forever. With probability $1-\rho(\Gamma)$ there is no investigation (and thus no chance of conviction) in the current period. Though firms outside of the cartel benefit from the higher prices - indeed, they price just below the collusive price - it is customary for them to be innocent of violating the law, and are typically not liable for customer damages. It is then assumed that they are not subject to penalties though will be harmed with the subsequent fall in prices due to antitrust enforcement shutting down the cartel.

As stated in A4, cartels with more members are assumed to have a higher probability of investigation and conviction.

A4 If $\Gamma^{\prime} \subset \Gamma^{\prime \prime}$ then $\rho\left(\Gamma^{\prime}\right)<\rho\left(\Gamma^{\prime \prime}\right)$, and if $i \notin \Gamma$ then $\lim _{k_{i} \rightarrow 0} \rho(\Gamma \cup\{i\})>\rho(\Gamma)$.

Thus, the probability of being caught is higher when a cartel adds firms, which strikes us as a natural assumption. The chances that the competition authority receives a complaint by a buyer is more likely when more buyers are affected which is the case when the cartel is more inclusive. If discovery comes from a cartel member inadvertently revealing information to an uninvolved employee within the firm then again this is more likely when more people are engaged in collusion which is true when there are more firms in the cartel. ${ }^{7}$ A4 also assumes the increase in probability from adding a firm to the cartel is bounded above zero even if the additional cartel member is arbitrarily small in terms of capacity (and, as a result, market share). This condition seems reasonable given that much of the reason why more members makes detection more likely is that there are more people with knowledge of the cartel and thus more opportunities for information to leak out, which is non-trivial even when a firm is very small. ${ }^{8}$

In case of discovery, a cartel member faces an antitrust penalty that is proportional to the profit it earned while colluding:

$$
\gamma(p-c)\left[D(p)-\left(K-K_{\Gamma}\right)\right]\left(\frac{k_{i}}{K_{\Gamma}}\right),
$$

where $\gamma>0$ is a penalty multiplier. ${ }^{9}$ Thus, larger cartel members face a larger penalty, all else equal. Many jurisdictions have a leniency program that gives cartel participants the opportunity to turn themselves in in exchange for a reduction of their penalty. To encompass such a program, assume that if firm $i$ is the first firm to

\footnotetext{
${ }^{7}$ One effect which may work in the other direction is that non-cartel members may provide a benchmark for determining that there is a cartel. Thus, an all-inclusive cartel could possibly be more difficult to detect.

${ }^{8} \mathrm{~A} 4$ also allows the probability of discovery and conviction to depend on the capacities of the cartel members though that is not a property that is used for any of our results. What the probability is not allowed to depend on are the prices and quantities. To our knowledge, the only dynamic model in which the cartel's price behavior affects the likelihood of the cartel paying penalties is Harrington (2004, 2005).

${ }^{9}$ This is a natural specification in jurisdictions that have customer damages. While customer damages are typically calculated in such a way that damages do not generally equal the incremental profit from collusion, incremental profits are still a good approximation. In jurisdictions where the primary penalty is government fines then this specification is more problematic because those fines are often based more on revenue than on profit.
} 
receive leniency then it pays a penalty equal to the expression in (1) multiplied by $\theta \in[0,1] . \theta$ is a policy parameter and includes the case of no leniency $(\theta=1)$ and full leniency $(\theta=0)$. Of course, in response to an investigation, all cartel members may simultaneously race for leniency in which case it is natural to suppose that each has an equal chance of receiving it. If leniency is given only to one firm then a firm can expect to pay the full penalty multiplied by $\frac{|\Gamma|-1+\theta}{|\Gamma|}$; each cartel member has

probability $\frac{1}{|\Gamma|}$ of receiving leniency and probability $\frac{|\Gamma|-1}{|\Gamma|}$ of not receiving leniency and paying the full penalty. To allow for such discounts - as well as other programs that may impact the penalties actually paid - it is assumed that, in response to an investigation, a cartel member can expect to pay a penalty equal to (1) multiplied by $\psi(\Gamma) \in(0,1]$. Hence, the expected penalty that firm $i \in \Gamma$ faces prior to learning whether or not there is an investigation is ${ }^{10}$

$$
\rho(\Gamma) \psi(\Gamma) \gamma(p-c)\left[D(p)-\left(K-K_{\Gamma}\right)\right]\left(\frac{k_{i}}{K_{\Gamma}}\right) .
$$

It is assumed $\psi(\Gamma)$ is weakly larger for cartels encompassing more members.

A5 If $\Gamma^{\prime} \subset \Gamma^{\prime \prime}$ then $\psi\left(\Gamma^{\prime}\right) \leq \psi\left(\Gamma^{\prime \prime}\right)$.

The special case of $\psi(\Gamma)=\frac{|\Gamma|-1+\theta}{|\Gamma|}$ obviously satisfies these conditions. ${ }^{11}$

\section{Cartel's Objective and Equilibrium Price}

Consider a cartel $\Gamma$ with a common cartel price $p>c+\varepsilon$. The collusive value for member $i \in \Gamma$, denoted $V_{i}(p, \Gamma)$, is defined recursively by

$$
\begin{aligned}
V_{i}(p, \Gamma)= & (p-c)\left[D(p)-\left(K-K_{\Gamma}\right)\right]\left(\frac{k_{i}}{K_{\Gamma}}\right) \\
& -\rho(\Gamma) \psi(\Gamma) \gamma(p-c)\left[D(p)-\left(K-K_{\Gamma}\right)\right]\left(\frac{k_{i}}{K_{\Gamma}}\right)+\delta(1-\rho(\Gamma)) V_{i}(p, \Gamma) .
\end{aligned}
$$

\footnotetext{
${ }^{10}$ While the expression in $(2)$ suggests that $\psi(\Gamma)$ is redundant because only $\rho(\Gamma) \psi(\Gamma)$ enters, we will soon present expressions that depend only on $\rho(\Gamma)$. For example, the expected payoff to a non-cartel member depends only on the probability of the cartel shutting down, $\rho(\Gamma)$, because it is not penalized.

${ }^{11}$ One might ask why leniency would be given in response to an investigation when conviction is assumed to occur for sure. One reason is that it saves on resources in prosecuting the case. Alternatively, we could specify $\rho(\Gamma)$ as the probability of an investigation and introduce $\omega$ as the probability of conviction when there is no leniency program; in that case, $\rho(\Gamma) \omega$ is the probability of paying penalties. When there is a leniency program (and presuming that, in response to an investigation, firms use it), $\psi(\Gamma)$ can then be interpreted as the probability of paying penalties multiplied by the fraction of penalties one must pay. Discounts due to leniency would tend to reduce $\psi(\Gamma)$ - which is referred to as the Cartel Amnesty effect in Harrington (2008) - and if conviction is more likely because firms come forward to cooperate then it would tend to cause $\psi(\Gamma)>\omega-$ which is referred to as the Race to the Courthouse effect in Harrington (2008).
} 
Solving it for $V_{i}(p, \Gamma)$ yields

$$
V_{i}(p, \Gamma)=k_{i}\left(\frac{1-\rho(\Gamma) \psi(\Gamma) \gamma}{1-\delta(1-\rho(\Gamma))}\right)(p-c)\left[\frac{D(p)-\left(K-K_{\Gamma}\right)}{K_{\Gamma}}\right]=k_{i} V(p, \Gamma) .
$$

Observe that firm $i$ 's value equals a common value per unit of capacity, $V(p, \Gamma)$, multiplied by its capacity: $V_{i}(p, \Gamma)=k_{i} V(p, \Gamma)$. When the cartel is not all-inclusive, non-cartel members optimally set their prices slightly below the cartel price and produce up to their capacity. Since $k_{i}<D\left(p^{m}\right) \forall i \in N$ (Assumption 3), this implies that a member that undercuts the collusive price optimally prices at $p-\varepsilon$ or $p-2 \varepsilon$. Specifically, it will choose $p-\varepsilon$ when it is capacity constrained at that price; otherwise it sets $p-2 \varepsilon$. As to the latter, the cheating firm would be charging the lowest price in the industry and is therefore capacity constrained by assumption. Consequently, cutting price further would be unprofitable. Thus, for $\varepsilon$ sufficiently small, a cheating firm $i \in \Gamma$ earns approximately $(p-c) k_{i}$ in terms of current profit and zero future profit (as all firms revert to static Nash equilibrium pricing). ${ }^{12}$ Finally, recall that there is still a chance of being caught in the period of defection so that cheating members remain subject to antitrust enforcement. A deviating firm therefore also has the possibility to simultaneously apply for leniency. ${ }^{13}$

Given a cartel $\Gamma$, the incentive compatibility constraint (ICC) for firm $i \in \Gamma$ is then

$$
\begin{aligned}
& \left(\frac{1-\rho(\Gamma) \psi(\Gamma) \gamma}{1-\delta(1-\rho(\Gamma))}\right)(p-c)\left[\frac{D(p)-\left(K-K_{\Gamma}\right)}{K_{\Gamma}}\right] k_{i} \\
\geq & (p-c) k_{i}-\min \{\rho(\Gamma) \psi(\Gamma), \theta\} \gamma(p-c)\left[\frac{D(p)-\left(K-K_{\Gamma}\right)}{K_{\Gamma}}\right] k_{i} .
\end{aligned}
$$

Rearranging, the ICC can be presented as

$$
\Omega(\Gamma) \equiv\left(\frac{1-\rho(\Gamma) \psi(\Gamma) \gamma}{1-\delta(1-\rho(\Gamma))}\right)+\min \{\rho(\Gamma) \psi(\Gamma), \theta\} \gamma \geq \frac{K_{\Gamma}}{D(p)-\left(K-K_{\Gamma}\right)} .
$$

Note that the ICC is the same for all cartel members. Whether a cheating firm finds it optimal to apply for leniency depends on the values of $\rho(\Gamma) \psi(\Gamma)$ and $\theta$. A deviating member finds it optimal to turn itself in (prior to any investigation) only when leniency is sufficiently generous $(\theta<\rho(\Gamma) \psi(\Gamma))$ and otherwise prefers not to self-report $(\theta>\rho(\Gamma) \psi(\Gamma)) .{ }^{14}$

The cartel's problem is to choose price to maximize cartel value per unit of capacity subject to the ICC:

\footnotetext{
${ }^{12}$ We conjecture that all results extend to when the cartel can be recreated in the future. For example, if the cartel comes back together in $T$ periods then

$$
V_{i}(p, \Gamma)=k_{i}\left(\frac{1-\rho(\Gamma) \psi(\Gamma) \gamma}{1-\delta+\left(\delta-\delta^{T}\right) \rho(\Gamma)}\right)(p-c)\left[\frac{D(p)-\left(K-K_{\Gamma}\right)}{K_{\Gamma}}\right]
$$

which is qualitatively similar to $(3)$.

${ }^{13}$ This is referred to as the Deviator Amnesty effect in Harrington (2008).

${ }^{14}$ Note that it is assumed a deviating firm pays a penalty proportional to its profit if it set the
} 


$$
p^{*}(\Gamma)=\arg \max \left(\frac{1-\rho(\Gamma) \psi(\Gamma) \gamma}{1-\delta(1-\rho(\Gamma))}\right)(p-c)\left[\frac{D(p)-\left(K-K_{\Gamma}\right)}{K_{\Gamma}}\right]
$$

subject to

$$
\Omega(\Gamma) \geq \frac{K_{\Gamma}}{D(p)-\left(K-K_{\Gamma}\right)} .
$$

Let $\widehat{p}(\Gamma)$ be the maximum price that satisfies the ICC:

$$
\widehat{p}(\Gamma) \equiv D^{-1}\left(K-K_{\Gamma}+\left(K_{\Gamma} / \Omega(\Gamma)\right)\right) .
$$

Hence, firms can only sustain a price above cost when

$$
D^{-1}\left(K-K_{\Gamma}+\left(K_{\Gamma} / \Omega(\Gamma)\right)\right)>c \Rightarrow \Omega(\Gamma)>\frac{K_{\Gamma}}{D(c)-\left(K-K_{\Gamma}\right)} .
$$

This condition is guaranteed to hold when $\rho(\Gamma) \rightarrow 0$ and $\delta \rightarrow 1$, provided that a sufficient amount of industry capacity is under the control of the cartel. Since the objective function is strictly concave,

$$
\frac{\partial^{2} V(p, \Gamma)}{\partial p^{2}}=\left(\frac{1-\rho(\Gamma) \psi(\Gamma) \gamma}{1-\delta(1-\rho(\Gamma))}\right)\left(\frac{2 D^{\prime}(p)+(p-c) D^{\prime \prime}(p)}{K_{\Gamma}}\right)<0,
$$

the first-order condition is sufficient to determine the non-binding solution. Let $p^{o}(\Gamma)$ denote the unconstrained optimal cartel price:

$$
D\left(p^{o}(\Gamma)\right)-\left(K-K_{\Gamma}\right)+\left(p^{o}(\Gamma)-c\right) D^{\prime}\left(p^{o}(\Gamma)\right)=0 .
$$

Observe that the unconstrained solution is independent of antitrust enforcement. Finally, since $V(p, \Gamma)$ is strictly concave in $p$, it follows that

$$
p^{*}(\Gamma)=\min \left\{\widehat{p}(\Gamma), p^{o}(\Gamma)\right\} .
$$

The equilibrium collusive value for a cartel $\Gamma$ is then

$$
V^{*}(\Gamma) \equiv V\left(p^{*}(\Gamma), \Gamma\right)=\left(\frac{1-\rho(\Gamma) \psi(\Gamma) \gamma}{1-\delta(1-\rho(\Gamma))}\right)\left(p^{*}(\Gamma)-c\right)\left[\frac{D\left(p^{*}(\Gamma)\right)-\left(K-K_{\Gamma}\right)}{K_{\Gamma}}\right]
$$

Prior to exploring the impact of antitrust enforcement on the inclusiveness of cartels, it is useful to gain some insight into its impact on the collusive price. In our previous work, the optimal cartel price was primarily determined by the amount

collusive price. If deviation occurred in the first period of collusion, it would seem more reasonable to assume that it is proportional to the profit it received while deviating. If deviation occurred after many periods of collusion then the penalty ought to be proportional to average profit during the time of the cartel which will be a weighted average of collusive profit (for the many periods of collusion) and deviation profit (for the one period of deviation) which will be close to collusive profit. We chose the latter specification since it describes the steady-state. However, we have no reason to think that our main results are sensitive to this assumption. 
of industry capacity controlled by the cartel, and the cartel price was shown to be increasing in cartel capacity (Theorem 3 in Bos and Harrington, 2010). In the current analysis, firms that take part in the collusive agreement incur expected penalties due to antitrust enforcement. The presence of antitrust enforcement potentially creates a trade-off when it comes to the effect of a more inclusive cartel on price. While a more inclusive cartel means less capacity is outside of the cartel, which tends to raise the collusive price, it also means higher expected penalties because the probability of discovery and conviction is higher ( $\rho$ is higher) and a firm is less likely to receive leniency ( $\psi$ is higher), which tends to lower the collusive price. With these two counter-acting forces of a more inclusive cartel, its impact on price is ambiguous. However, pertinent to the ensuing analysis, we can show that more intense antitrust enforcement will tend to reduce the optimal cartel price by tightening the ICC. Thus, for a given cartel, a stricter antitrust regime leads to a weakly lower cartel price.

Theorem 1 For any given cartel $\Gamma, p^{*}(\Gamma)$ is non-increasing in $\rho(\Gamma), \psi(\Gamma)$, and $\gamma$. If $p^{*}(\Gamma)<p^{o}(\Gamma)$, then $p^{*}(\Gamma)$ is decreasing in $\rho(\Gamma), \psi(\Gamma)$, and $\gamma$.

Proof. If the ICC is not binding, then $p^{*}(\Gamma)$ is independent of $\rho(\Gamma), \psi(\Gamma)$, and $\gamma$. If the ICC is binding, then $p^{*}(\Gamma)$ satisfies

$$
\Omega(\Gamma)=\frac{K_{\Gamma}}{D\left(p^{*}(\Gamma)\right)-\left(K-K_{\Gamma}\right)}
$$

where $\Omega(\Gamma)$ is defined in (4). If $\theta<\rho(\Gamma) \psi(\Gamma)$, then

$$
\begin{aligned}
& \frac{\partial \Omega(\Gamma)}{\partial \rho(\Gamma)}=-\left(\frac{\psi(\Gamma) \gamma(1-\delta)+\delta}{[1-\delta(1-\rho(\Gamma))]^{2}}\right)<0, \frac{\partial \Omega(\Gamma)}{\partial \psi(\Gamma)}=-\frac{\rho(\Gamma) \gamma}{1-\delta(1-\rho(\Gamma))}<0 \\
& \frac{\partial \Omega(\Gamma)}{\partial \gamma}=-\left(\frac{\rho(\Gamma) \psi(\Gamma)-\theta+\delta \theta(1-\rho(\Gamma))}{1-\delta(1-\rho(\Gamma))}\right)<0 .
\end{aligned}
$$

If $\theta>\rho(\Gamma) \psi(\Gamma)$, then

$$
\begin{aligned}
& \frac{\partial \Omega(\Gamma)}{\partial \rho(\Gamma)}=-\left(\frac{\psi(\Gamma) \gamma \delta(1-\rho(\Gamma))[1-\delta(1-\rho(\Gamma))]+\delta(1-\rho(\Gamma) \psi(\Gamma) \gamma)}{[1-\delta(1-\rho(\Gamma))]^{2}}\right)<0 \\
& \frac{\partial \Omega(\Gamma)}{\partial \psi(\Gamma)}=-\frac{\delta(1-\rho(\Gamma)) \rho(\Gamma) \gamma}{1-\delta(1-\rho(\Gamma))}<0, \frac{\partial \Omega(\Gamma)}{\partial \gamma}=-\frac{\delta(1-\rho(\Gamma)) \rho(\Gamma) \psi(\Gamma)}{1-\delta(1-\rho(\Gamma))}<0 .
\end{aligned}
$$

Given that $\Omega(\Gamma)$ is decreasing in $\rho(\Gamma), \psi(\Gamma)$, and $\gamma$, then, at higher values for those parameters, (7) implies

$$
\Omega(\Gamma)<\frac{K_{\Gamma}}{D\left(p^{*}(\Gamma)\right)-\left(K-K_{\Gamma}\right)} .
$$

It follows that $p^{*}(\Gamma)$ must decline so that $D\left(p^{*}(\Gamma)\right)$ is increased and $\frac{K_{\Gamma}}{D\left(p^{*}(\Gamma)\right)-\left(K-K_{\Gamma}\right)}$ is decreased in order to satisfy the ICC. 
Consistent with other work, more intense antitrust enforcement (weakly) reduces the cartel price, holding the composition of the cartel fixed. Previous research typically assumes the cartel is all-inclusive and is unresponsive to antitrust enforcement (with the exception of when enforcement is increased so much that collusion is no longer sustainable). The remainder of the analysis of this paper will explore how antitrust enforcement affects how inclusive is the cartel.

\section{Defining the Set of Stable Cartels}

Let us now direct our attention to cartel formation and identifying what coalition configurations are stable. d'Aspremont et al (1983) were among the first to provide a clear and intuitive notion of cartel stability. A cartel is considered to be stable when (i) none of its members wants to leave the cartel (internal stability) and (ii) none of the non-cartel members wants to join the cartel (external stability).

To derive the exact conditions in our model for a cartel to be both internally and externally stable, consider some candidate cartel $\Gamma$. The equilibrium value to firm $i$ is $k_{i} V^{*}(\Gamma)$ when $i \in \Gamma$ and is $\frac{\left[p^{*}(\Gamma)-c\right] k_{i}}{1-\delta(1-\rho(\Gamma))}$ when $i \notin \Gamma$. Define $W_{i}(\Gamma)$ to be the equilibrium value to firm $i$ when $i \in \Gamma$ and it does not join the cartel, and when $i \notin \Gamma$ and it joins the cartel. $W_{i}(\Gamma)$ is then the payoff that firm $i$ expects if it acts contrary to expectations about cartel membership, whether it means not joining the cartel when it should have or joining the cartel when it should not have. ${ }^{15}$ With these equilibrium values, a cartel is stable when all cartel members strictly prefer to be a member (internal stability) and all non-members weakly prefer not to be a member (external stability). Internal stability requires a strict preference for cartel membership in order to rule out the trivial case in which firms are members of a cartel but the cartel prices the same as when there is no cartel (that is, at cost). ${ }^{16}$

Definition 2 A cartel $\Gamma$ is stable if: i) $k_{i} V^{*}(\Gamma)>W_{i}(\Gamma)$ for all $i \in \Gamma$; and ii) $\frac{\left[p^{*}(\Gamma)-c\right] k_{i}}{1-\delta(1-\rho(\Gamma))} \geq W_{i}(\Gamma)$ for all $i \notin \Gamma$.

In specifying $W_{i}(\Gamma)$, it is standard in the literature (including our earlier paper) to assume that, regardless of firms' decisions as to whether or not to join the cartel, the resulting cartel acts according to the equilibrium yielding the highest collusive value. While that is a natural specification when firms act according to expectations with respect to the cartel membership decision, there could be other reasonable responses

\footnotetext{
${ }^{15}$ In thinking about a firm joining a cartel for which it was not expected to be a member, the issue is not whether a firm can force its way into a cartel but rather whether it desires to join a cartel for which it was not expected to be a member. As it turns out, if the existing members of a cartel find it unprofitable for an outsider to join then that outsider will find it unprofitable as well; thus, a firm will never want to try and force itself on a cartel. The problematic situation is when a firm prefers not to join a cartel and existing cartel members would like for it to join.

${ }^{16}$ This definition presumes that firms, in deciding whether to join or leave a cartel, take as given the membership decisions of the other firms. That is, a firm that considers a change in membership assumes that insiders remain insiders and outsiders remain outsiders. Relaxing this assumption, albeit potentially interesting, would significantly complicate the analysis. See Bos and Harrington (2010) for a discussion of this issue.
} 
when firms do not act according to expectations, either by not joining a cartel for which it was supposed to be a member or joining a cartel for which it was not supposed to be a member. A novel feature of our approach is to consider various equilibria in response to such events. One equilibrium is the standard specification: the cartel accommodates the disequilibrium membership decision by achieving the maximal level of collusion given whichever firms are in the cartel. We refer to this as the accommodative equilibrium and it implies:

$$
\text { if } i \in \Gamma \text { then } W_{i}(\Gamma)=\frac{\left[p^{*}(\Gamma \backslash\{i\})-c\right] k_{i}}{1-\delta(1-\rho(\Gamma \backslash\{i\}))}
$$

and

$$
\text { if } i \notin \Gamma \text { then } W_{i}(\Gamma)=k_{i} V^{*}(\Gamma \cup\{i\}) .
$$

An alternative equilibrium is that the cartel responds in a punishing manner by disbanding so that all firms receive the static Nash equilibrium payoff. Referring to it as the aggressive equilibrium, $W_{i}(\Gamma)=0 \forall i$. There are other equilibria one could consider.

In performing an equilibrium selection, we are guided by the objective of this paper which is to assess the effect of antitrust enforcement on the range of stable cartels. Hence, we will consider the most expansive set of cartels. Given that the aggressive equilibrium is the equilibrium with the lowest payoffs, if a cartel is not stable with the aggressive equilibrium then it is not stable with any other equilibrium. This then argues to specifying the aggressive equilibrium. However, one modification to that specification is appropriate on plausibility grounds. It would seem nonsensical for a cartel to punish a cartel member for departing or a non-cartel member for joining when such an action actually improves the payoffs of cartel members. Thus, when entry into (exit from) the cartel enhances the value of the original (remaining) members of the cartel, it is assumed that the accommodative equilibrium ensues. This assumption is embodied in the following two conditions used in evaluating the stability of cartel $\Gamma$. First,

$$
\text { if } i \notin \Gamma \text { and } V^{*}(\Gamma \cup\{i\})>V^{*}(\Gamma) \text { then } W_{i}(\Gamma)=k_{i} V^{*}(\Gamma \cup\{i\}) \text {; }
$$

that is, if an outsider joining the cartel raises each original cartel member's payoff under the supposition of the accommodative equilibrium then cartel members do in fact respond with the accommodative equilibrium. Second,

$$
\text { if } i \in \Gamma \text { and } V^{*}(\Gamma \backslash\{i\})>V^{*}(\Gamma) \text { then } W_{i}(\Gamma)=\frac{\left[p^{*}(\Gamma \backslash\{i\})-c\right] k_{i}}{1-\delta(1-\rho(\Gamma \backslash\{i\}))} \text {; }
$$

that is, if an insider leaving the cartel raises each remaining cartel member's payoff under the supposition of the accommodative equilibrium then cartel members do in fact respond with the accommodative equilibrium. For all other cases, cartel members respond with the aggressive equilibrium so $W_{i}(\Gamma)=0$. 


\section{Impact of a Competition Authority on the Set of Sta- ble Cartels}

First note that if antitrust enforcement is sufficiently strong then no cartels are stable because collusion is ineffective at sustaining prices above the non-collusive price. That is not the scenario examined here. Instead, we are considering when stable cartels still exist and asking whether they tend to be larger or smaller compared to the absence of antitrust enforcement. Given that there can be many stable cartels, the analysis will focus on the impact on the range of cartel size. ${ }^{17}$ For this purpose, we define:

Definition $3 \Gamma^{\prime}$ is a minimal stable cartel if $\Gamma^{\prime}$ is stable and $\Gamma$ is not a stable cartel for all $\Gamma \subset \Gamma^{\prime}$.

Definition $4 \Gamma^{\prime}$ is a maximal stable cartel if $\Gamma^{\prime}$ is stable and $\Gamma$ is not a stable cartel for all $\Gamma \supset \Gamma^{\prime}$.

A minimal stable cartel is a stable cartel for which there is no sub-coalition of that cartel which is stable, while a maximal stable cartel is a stable cartel for which there is no super-coalition containing that cartel which is stable. There can be multiple minimal and maximal stable cartels.

The impact of antitrust enforcement on the size of maximal stable cartels is examined in Section 5.1 and on the size of minimal stable cartels in Section 5.2. It'll be shown that competition policy can reduce the size of the largest cartels but, depending on the circumstances, can either increase or decrease the size of the smallest cartels.

\subsection{Maximal Cartel Size}

The task is to compare the size of maximal stable cartels with and without antitrust enforcement. As a benchmark, Lemma 5 shows that if collusion is sustainable in the absence of a competition authority - for which $\delta>\frac{K-D(c)}{K}$ is a necessary and sufficient condition - then there is a unique maximal cartel and it is the all-inclusive cartel. ${ }^{18}$

Lemma 5 Assume $\delta>\frac{K-D(c)}{K}$. In the absence of antitrust enforcement, the maximal stable cartel is the all-inclusive cartel.

Proof. Theorem 4 in Bos and Harrington (2010) shows that the cartel value without antitrust enforcement, $V^{*}(\Gamma)$, is greater when the cartel is more inclusive: if $\Gamma^{\prime} \subset \Gamma^{\prime \prime}$ then $V^{*}\left(\Gamma^{\prime \prime}\right)>V^{*}\left(\Gamma^{\prime}\right)$. Consider the all-inclusive cartel: $\Gamma=N$. As there are no outsiders, it is trivially externally stable. By assuming $W_{i}(\Gamma)=0$ - that is, an

\footnotetext{
${ }^{17}$ It is common in these types of models that there can be multiple stable cartels; see, for example, Donsimoni (1985), Donsimoni et al (1986) and Diamantoudi (2005).

${ }^{18}$ We did not necessarily find the all-inclusive cartel to be stable in Bos and Harrington (2010) because the accommodative equilibrium was used in assessing internal stability. Here, we assume the aggressive equilibrium except where previously noted.
} 
insider who leaves the cartel can expect the static Nash equilibrium - it follows from $V^{*}(N)>0$ that it is internally stable. Therefore, $N$ is stable in the absence of antitrust enforcement.

It is an immediate corollary that antitrust enforcement cannot cause the largest stable cartel to be more inclusive. Thus, the issue is whether it can cause the largest stable cartel to contract. While the all-inclusive cartel generates the highest profits without antitrust enforcement, this may no longer be true with an antitrust authority because expected penalties are increasing in cartel size. While each additional member to the cartel adds value for the original cartel members by restricting its supply below its capacity, it also creates a cost to those original members by increasing the probability of discovery and conviction (and perhaps reducing the chances of an original member receiving leniency since now there will be more firms striving for it). Given that the impact on the collusive price from a firm joining a cartel is positively related to firm size - a larger firm brings more capacity under the control of the cartel which means output is restricted more and price rises more - a sufficiently small firm may not raise the collusive price enough to offset having increased expected penalties. As a result, a small firm earns higher profit outside of the cartel which is the case whether or not there is antitrust enforcement - and, in addition, the remaining cartel members also earn higher profit when a small firm remains outside of the cartel - which is only true when there is antitrust enforcement and is because expected penalties are lower.

Theorem 6 In the presence of antitrust enforcement, $\exists \underline{k}>0$ such that if $k_{n}<\underline{k}$ then a maximal stable cartel excludes firm n.

Proof. If $p^{*}(N)=c$ then the theorem is true because $N$ is not a stable cartel and thus cannot be a maximal stable cartel. Thus, for the remainder of the proof, suppose $p^{*}(N)>c$ so that a collusive price can be sustained with the all-inclusive cartel. Let us derive sufficient conditions for cartel $N$ not to be stable.

The collusive value per unit of capacity for the all-inclusive cartel is

$$
V^{*}(N)=\left(\frac{1-\rho(N) \psi(N) \gamma}{1-\delta(1-\rho(N))}\right)\left(p^{*}(N)-c\right)\left(\frac{D\left(p^{*}(N)\right)}{K}\right)
$$

and recall that the value to firm $i$ is $k_{i} V^{*}(N)$. Let us contrast this with the collusive value per unit of capacity for the cartel that excludes firm $n$. Letting $\Delta \equiv N \backslash\{n\}$ then

$$
V^{*}(\Delta)=\left(\frac{1-\rho(\Delta) \psi(\Delta) \gamma}{1-\delta(1-\rho(\Delta))}\right)\left(p^{*}(\Delta)-c\right)\left(\frac{D\left(p^{*}(\Delta)\right)-k_{n}}{K-k_{n}}\right)
$$

which means a cartel member $i \in \Delta$ earns $k_{i} V^{*}(\Delta)$. Comparing (9) with (8), the less than all inclusive cartel $\Delta$ generates more value than the all-inclusive cartel when:

$$
\left(\frac{1-\rho(\Delta) \psi(\Delta) \gamma}{1-\delta(1-\rho(\Delta))}\right)\left(p^{*}(\Delta)-c\right)\left(\frac{D\left(p^{*}(\Delta)\right)-k_{n}}{K-k_{n}}\right)>\left(\frac{1-\rho(N) \psi(N) \gamma}{1-\delta(1-\rho(N))}\right)\left(p^{*}(N)-c\right)\left(\frac{D\left(p^{*}(N)\right)}{K}\right) .
$$


Rearranging yields:

$$
\frac{\left(p^{*}(\Delta)-c\right)\left(\frac{D\left(p^{*}(\Delta)\right)-k_{n}}{K-k_{n}}\right)}{\left(p^{*}(N)-c\right)\left(\frac{D\left(p^{*}(N)\right)}{K}\right)}>\frac{(1-\rho(N) \psi(N) \gamma)(1-\delta(1-\rho(\Delta)))}{(1-\rho(\Delta) \psi(\Delta) \gamma)(1-\delta(1-\rho(N)))} .
$$

Consider the LHS as $k_{n} \rightarrow 0$,

$$
\lim _{k_{n} \rightarrow 0} \frac{\left(p^{*}(\Delta)-c\right)\left(\frac{D\left(p^{*}(\Delta)\right)-k_{n}}{K-k_{n}}\right)}{\left(p^{*}(N)-c\right)\left(\frac{D\left(p^{*}(N)\right)}{K}\right)}=\lim _{k_{n} \rightarrow 0} \frac{\left(p^{*}(\Delta)-c\right) D\left(p^{*}(\Delta)\right)}{\left(p^{*}(N)-c\right) D\left(p^{*}(N)\right)} .
$$

When $\rho(\cdot)=0, \lim _{k_{n} \rightarrow 0} p^{*}(\Delta)=\lim _{k_{n} \rightarrow 0} p^{*}(N)$. By Theorem 1, $\rho(\cdot)>0$ implies $\lim _{k_{n} \rightarrow 0} p^{*}(\Delta) \geq \lim _{k_{n} \rightarrow 0} p^{*}(N)$ because, as $k_{n} \rightarrow 0$, cartel $N$ is equivalent to cartel $\Delta$ but with $\rho=\rho(N)$. Therefore, $\lim _{k_{n} \rightarrow 0}\left(p^{*}(\Delta)-c\right) D\left(p^{*}(\Delta)\right) \geq \lim _{k_{n} \rightarrow 0}\left(p^{*}(N)-\right.$ c) $D\left(p^{*}(N)\right)$ which implies the LHS of (10) is at least one. Next consider the RHS of (10). Re-arranging the expression, it is strictly less than one iff

$\delta[\rho(N)-\rho(\Delta)]+(1-\delta) \gamma[\rho(N) \psi(N)-\rho(\Delta) \psi(\Delta)]+\delta \rho(N) \rho(\Delta) \gamma[\psi(N)-\psi(\Delta)]>0$.

This condition holds because of A4 and A5: $\lim _{k_{n} \rightarrow 0} \rho(N)>\lim _{k_{n} \rightarrow 0} \rho(\Delta)$ and $\psi(N) \geq \psi(\Delta)$. We have then shown that the firms in $\Delta$ earn a higher payoff when firm $n$ is not a member of the cartel, compared to when it is a member. By our specification, this implies that if firm $n$ departs from cartel $N$ then the remaining cartel members respond with the accommodative equilibrium.

The second step is to show that firm $n$ prefers to depart from cartel $N$ when the accommodative equilibrium ensues in which case $N$ is not internally stable. Firm $n$ 's payoff in the cartel is

$$
\left(\frac{1-\rho(N) \psi(N) \gamma}{1-\delta(1-\rho(N))}\right)\left(p^{*}(N)-c\right)\left(\frac{D\left(p^{*}(N)\right)}{K}\right) k_{n}
$$

and outside of the cartel is

$$
\frac{\left(p^{*}(\Delta)-c\right) k_{n}}{1-\delta(1-\rho(\Delta))}
$$

Given that

$$
\frac{1}{1-\delta(1-\rho(\Delta))}>\frac{1-\rho(N) \psi(N) \gamma}{1-\delta(1-\rho(N))}
$$

then (12) exceeds (11) if

$$
\begin{gathered}
\left(p^{*}(\Delta)-c\right) k_{n} \geq\left(p^{*}(N)-c\right)\left(\frac{D\left(p^{*}(N)\right)}{K}\right) k_{n} \\
p^{*}(\Delta)-c \geq\left(p^{*}(N)-c\right)\left(\frac{D\left(p^{*}(N)\right)}{K}\right)
\end{gathered}
$$

Given $\lim _{k_{n} \rightarrow 0} p^{*}(\Delta) \geq \lim _{k_{n} \rightarrow 0} p^{*}(N)$ then this condition holds. 
In sum, as $k_{n} \rightarrow 0$, cartel $N$ is not stable because firm $n$ finds it more profitable to be outside of the cartel assuming the cartel accommodates its departure and, given the remaining cartel members are better off with the departure, they do indeed accommodate it.

We then find that antitrust enforcement can result in less inclusive cartels because the smallest firms may not be members. The next natural question to ask is: What is the effect on price from the cartel being made less inclusive because of the presence of a competition authority? If the cartel can sustain the unconstrained collusive price then excluding smaller firms must result in a lower price; the unconstrained collusive price is independent of antitrust enforcement and is lower when the cartel controls less capacity. However, when the collusive price is determined by the ICC, the effect of a less inclusive cartel on price is unclear. Offsetting the price-reducing effect of the cartel controlling less capacity, collusive value is higher which loosens the ICC and could possibly allow for a higher collusive price. Sorting out those conflicting forces is a topic for future research.

Thus far we've shown that maximal cartels are less inclusive in the presence of a competition authority. The basis for this result is that collusive value per unit of capacity for cartel members is maximized by excluding the smallest firms. Building on that finding, let us characterize how more intense enforcement - as reflected in a higher penalty multiple - impacts the characteristics of the most profitable cartel. For this purpose, define an ordering $\succ$ of cartels: $\Gamma^{\prime \prime} \succ \Gamma^{\prime}$ if and only if $\rho\left(\Gamma^{\prime \prime}\right) \geq \rho\left(\Gamma^{\prime}\right)$, $\psi\left(\Gamma^{\prime \prime}\right) \geq \psi\left(\Gamma^{\prime}\right)$, and $K_{\Gamma^{\prime \prime}} \geq K_{\Gamma^{\prime}}$ and one of the inequalities is strict. Thus, cartels are ranked according to the probability of paying penalties, penalty discount (which is $1-\psi$ ), and capacity. Generally, less inclusive cartels will have a lower probability of paying penalties, a higher discount, and lower capacity. ${ }^{19}$

Under the assumptions of full leniency and approximately linear demand, the next result shows that, in response to more severe penalties, the cartel that maximizes value per unit of cartel capacity is a cartel that is (weakly) "smaller" in the sense of controlling less capacity, having a lower probability of paying penalties, and having a higher discount on penalties. ${ }^{20}$

Theorem 7 Assume $\theta=0$ and demand is approximately linear $\left(D^{\prime \prime}(\cdot) \simeq 0\right)$. Define $\Gamma^{*}(\gamma)$ as the most profitable stable cartel (in terms of value per unit of capacity). If $\succ$ is complete and $\gamma^{\prime \prime}>\gamma^{\prime}$ then $\rho\left(\Gamma^{*}\left(\gamma^{\prime}\right)\right) \geq \rho\left(\Gamma^{*}\left(\gamma^{\prime \prime}\right)\right), \psi\left(\Gamma^{*}\left(\gamma^{\prime}\right)\right) \geq \psi\left(\Gamma^{*}\left(\gamma^{\prime \prime}\right)\right)$, and $K_{\Gamma^{*}\left(\gamma^{\prime}\right)} \geq K_{\Gamma^{*}\left(\gamma^{\prime \prime}\right)}$; that is, in response to higher penalties, the most profitable stable cartel has a (weakly) lower probability of paying penalties, higher discount, and lower capacity.

Proof. The proof strategy is to show that if $\Gamma^{\prime \prime} \succ \Gamma^{\prime}$ and $V^{*}\left(\Gamma^{\prime} ; \gamma^{\prime}\right)>V^{*}\left(\Gamma^{\prime \prime} ; \gamma^{\prime}\right)$ (where we have made explicit the value for $\gamma$ ) then $V^{*}\left(\Gamma^{\prime} ; \gamma^{\prime \prime}\right)>V^{*}\left(\Gamma^{\prime \prime} ; \gamma^{\prime \prime}\right)$ where $\gamma^{\prime \prime}>\gamma^{\prime}$. That is, if cartel $\Gamma^{\prime}$ is more profitable than cartel $\Gamma^{\prime \prime}$ and cartel $\Gamma^{\prime}$ has a lower

\footnotetext{
${ }^{19}$ If it is assumed all firms have equal capacity then this ordering is complete and cartels are ranked according to the number of firms, $|\Gamma|$.

${ }^{20}$ While we have no reason to believe that the result fails to hold when leniency is less than full and demand is not linear, we have been unable to prove the result more generally.
} 
probability of paying penalties $\left(\rho\left(\Gamma^{\prime \prime}\right) \geq \rho\left(\Gamma^{\prime}\right)\right)$, a higher discount $\left(\psi\left(\Gamma^{\prime \prime}\right) \geq \psi\left(\Gamma^{\prime}\right)\right)$, and controls less capacity $\left(K_{\Gamma^{\prime \prime}} \geq K_{\Gamma^{\prime}}\right)$ then cartel $\Gamma^{\prime}$ will continue to be more profitable when penalties are higher. With that result, it can then be argued that the most profitable cartel must be "smaller" (in the sense of the ordering) when $\gamma$ is higher. For suppose the most profitable cartel when $\gamma=\gamma^{\prime}$ is $\Gamma^{*}\left(\gamma^{\prime}\right): V^{*}\left(\Gamma^{*}\left(\gamma^{\prime}\right) ; \gamma^{\prime}\right)>$ $V^{*}\left(\Gamma ; \gamma^{\prime}\right) \forall \Gamma$. When $\gamma$ is increased to $\gamma^{\prime \prime}$, it must then still be the case that $\Gamma^{*}\left(\gamma^{\prime}\right)$ is more profitable than "larger" cartels $-V^{*}\left(\Gamma^{*}\left(\gamma^{\prime}\right) ; \gamma^{\prime \prime}\right)>V^{*}\left(\Gamma ; \gamma^{\prime \prime}\right) \forall \Gamma$ such that $\Gamma \succ \Gamma^{*}\left(\gamma^{\prime}\right)$ - which then implies that the most profitable cartel must be (weakly) "smaller" than $\Gamma^{*}\left(\gamma^{\prime}\right)$.

Using the expression for $V^{*}(\Gamma)$, cartel $\Gamma^{\prime}$ generates higher value (per unit of cartel capacity) than $\Gamma^{\prime \prime}$ when

$$
\begin{aligned}
& \left(\frac{1-\rho\left(\Gamma^{\prime}\right) \psi\left(\Gamma^{\prime}\right) \gamma}{1-\delta\left(1-\rho\left(\Gamma^{\prime}\right)\right)}\right)\left(p^{*}\left(\Gamma^{\prime}\right)-c\right)\left(\frac{D\left(p^{*}\left(\Gamma^{\prime}\right)\right)-\left(K-K_{\Gamma^{\prime}}\right)}{K_{\Gamma^{\prime}}}\right) \\
> & \left(\frac{1-\rho\left(\Gamma^{\prime \prime}\right) \psi\left(\Gamma^{\prime \prime}\right) \gamma}{1-\delta\left(1-\rho\left(\Gamma^{\prime \prime}\right)\right)}\right)\left(p^{*}\left(\Gamma^{\prime \prime}\right)-c\right)\left(\frac{D\left(p^{*}\left(\Gamma^{\prime \prime}\right)\right)-\left(K-K_{\Gamma^{\prime \prime}}\right)}{K_{\Gamma^{\prime \prime}}}\right) .
\end{aligned}
$$

Re-arranging, we have

$$
\begin{aligned}
& \left(\frac{1-\rho\left(\Gamma^{\prime}\right) \psi\left(\Gamma^{\prime}\right) \gamma}{1-\delta\left(1-\rho\left(\Gamma^{\prime}\right)\right)}\right)\left(\frac{1-\delta\left(1-\rho\left(\Gamma^{\prime \prime}\right)\right)}{1-\rho\left(\Gamma^{\prime \prime}\right) \psi\left(\Gamma^{\prime \prime}\right) \gamma}\right) \\
> & \left(\frac{p^{*}\left(\Gamma^{\prime \prime}\right)-c}{p^{*}\left(\Gamma^{\prime}\right)-c}\right)\left(\frac{D\left(p^{*}\left(\Gamma^{\prime \prime}\right)\right)-\left(K-K_{\Gamma^{\prime \prime}}\right)}{D\left(p^{*}\left(\Gamma^{\prime}\right)\right)-\left(K-K_{\Gamma^{\prime}}\right)}\right)\left(\frac{K_{\Gamma^{\prime}}}{K_{\Gamma^{\prime \prime}}}\right)
\end{aligned}
$$

The task is to show that if (13) holds and $\rho\left(\Gamma^{\prime \prime}\right) \geq \rho\left(\Gamma^{\prime}\right), \psi\left(\Gamma^{\prime \prime}\right) \geq \psi\left(\Gamma^{\prime}\right)$, and $K_{\Gamma^{\prime \prime}} \geq$ $K_{\Gamma^{\prime}}$ then (13) continues to hold when $\gamma$ is increased. This result will be shown for two cases. First, when the collusive price is the unconstrained cartel price: $p^{*}(\Gamma)=$ $p^{o}(\Gamma)$. Second, when the collusive price is the constrained cartel price, $p^{*}(\Gamma)=\widehat{p}(\Gamma)$, and there is full leniency $(\theta=0)$ and demand is approximately linear. ${ }^{21}$

Suppose the ICC is not binding at the collusive price, in which case the collusive price $p^{*}(\Gamma)$ is defined by (5) and thus is independent of $\gamma$. Let us show that if (13) holds and $\rho\left(\Gamma^{\prime \prime}\right) \geq \rho\left(\Gamma^{\prime}\right), \psi\left(\Gamma^{\prime \prime}\right) \geq \psi\left(\Gamma^{\prime}\right)$, and $K_{\Gamma^{\prime \prime}} \geq K_{\Gamma^{\prime}}$ then it continues to hold when $\gamma$ is increased. Since the RHS of (13) is unchanged by increasing $\gamma$, we need only show that raising $\gamma$ does not decrease the LHS of (13). Take the derivative of the LHS of (13):

$$
\begin{aligned}
\frac{\partial \cdot}{\partial \gamma}= & \left\{-\rho\left(\Gamma^{\prime}\right) \psi\left(\Gamma^{\prime}\right)\left[1-\delta\left(1-\rho\left(\Gamma^{\prime \prime}\right)\right)\right]\left[1-\delta\left(1-\rho\left(\Gamma^{\prime}\right)\right)\right]\left[1-\rho\left(\Gamma^{\prime \prime}\right) \psi\left(\Gamma^{\prime \prime}\right) \gamma\right]\right. \\
& \left.+\left[1-\rho\left(\Gamma^{\prime}\right) \psi\left(\Gamma^{\prime}\right) \gamma\right]\left[1-\delta\left(1-\rho\left(\Gamma^{\prime \prime}\right)\right)\right]\left[1-\delta\left(1-\rho\left(\Gamma^{\prime}\right)\right)\right] \rho\left(\Gamma^{\prime \prime}\right) \psi\left(\Gamma^{\prime \prime}\right)\right\} \times \\
& \left\{\left[1-\delta\left(1-\rho\left(\Gamma^{\prime}\right)\right)\right]\left[1-\rho\left(\Gamma^{\prime \prime}\right) \psi\left(\Gamma^{\prime \prime}\right) \gamma\right]\right\}^{-2}
\end{aligned}
$$

\footnotetext{
${ }^{21}$ The difficulty in deriving a more general result in the second case is that changing $\gamma$ affects the ICC and thus affects the collusive price, while that is not the case when the ICC is not binding. While we conjecture the result is more general, a proof has thus far eluded us.
} 
Next note that:

$$
\begin{aligned}
\operatorname{sign}\left\{\frac{\partial \cdot}{\partial \gamma}\right\} & =\operatorname{sign}\left\{-\rho\left(\Gamma^{\prime}\right) \psi\left(\Gamma^{\prime}\right)\left[1-\rho\left(\Gamma^{\prime \prime}\right) \psi\left(\Gamma^{\prime \prime}\right) \gamma\right]+\left[1-\rho\left(\Gamma^{\prime}\right) \psi\left(\Gamma^{\prime}\right) \gamma\right] \rho\left(\Gamma^{\prime \prime}\right) \psi\left(\Gamma^{\prime \prime}\right)\right\} \\
& =\operatorname{sign}\left\{\rho\left(\Gamma^{\prime \prime}\right) \psi\left(\Gamma^{\prime \prime}\right)-\rho\left(\Gamma^{\prime}\right) \psi\left(\Gamma^{\prime}\right)\right\}
\end{aligned}
$$

Thus, if $\rho\left(\Gamma^{\prime \prime}\right) \geq \rho\left(\Gamma^{\prime}\right)$ and $\psi\left(\Gamma^{\prime \prime}\right) \geq \psi\left(\Gamma^{\prime}\right)$ then sign $\left\{\frac{\partial \cdot}{\partial \gamma}\right\} \geq 0$. Hence, when collusive prices are unconstrained, if collusive value is higher with $\Gamma^{\prime}$ than with $\Gamma^{\prime \prime}$, and $\Gamma^{\prime}$ involves a weakly lower probability of paying penalties, $\rho\left(\Gamma^{\prime \prime}\right) \geq \rho\left(\Gamma^{\prime}\right)$, and a weakly higher discount on penalties, $\psi\left(\Gamma^{\prime \prime}\right) \geq \psi\left(\Gamma^{\prime}\right)$, then collusive value is still higher with $\Gamma^{\prime}$ than with $\Gamma^{\prime \prime}$ after $\gamma$ is increased. Therefore, more severe penalties result in cartel value being maximized by a cartel with a lower probability of conviction.

Now suppose collusive prices are determined by a binding ICC. $p^{*}(\Gamma)$ is then defined by:

$$
\Omega(\Gamma) \equiv\left(\frac{1-\rho(\Gamma) \psi(\Gamma) \gamma}{1-\delta(1-\rho(\Gamma))}\right)+\min \{\rho(\Gamma) \psi(\Gamma), \theta\} \gamma=\frac{K_{\Gamma}}{D\left(p^{*}(\Gamma)\right)-\left(K-K_{\Gamma}\right)} .
$$

Substituting (14) into $V^{*}(\Gamma)$ from (6):

$$
\begin{aligned}
V^{*}(\Gamma) & =\left(\frac{1-\rho(\Gamma) \psi(\Gamma) \gamma}{1-\delta(1-\rho(\Gamma))}\right)\left(p^{*}(\Gamma)-c\right)\left[\frac{D\left(p^{*}(\Gamma)\right)-\left(K-K_{\Gamma}\right)}{K_{\Gamma}}\right] \\
& =\left(\frac{1-\rho(\Gamma) \psi(\Gamma) \gamma}{[1-\delta(1-\rho(\Gamma))] \Omega(\Gamma)}\right)\left(p^{*}(\Gamma)-c\right) .
\end{aligned}
$$

It is not difficult to show that $V^{*}(\Gamma)$ is decreasing in $\gamma$; that is, more severe penalties lower the collusive value for any given cartel. However, what we want to show is: if $\rho\left(\Gamma^{\prime \prime}\right) \geq \rho\left(\Gamma^{\prime}\right), \psi\left(\Gamma^{\prime \prime}\right) \geq \psi\left(\Gamma^{\prime}\right)$, and $K_{\Gamma^{\prime \prime}} \geq K_{\Gamma^{\prime}}$ (and one of them holds strictly) then $V^{*}\left(\Gamma^{\prime}\right)$ is less sensitive to $\gamma$ than is $V^{*}\left(\Gamma^{\prime \prime}\right)$. That will then imply: if $V^{*}\left(\Gamma^{\prime}\right)>V^{*}\left(\Gamma^{\prime \prime}\right)$ then, after $\gamma$ is increased, it is still the case that $V^{*}\left(\Gamma^{\prime}\right)>V^{*}\left(\Gamma^{\prime \prime}\right)$. Take the derivative of (15) with respect to $\gamma$.

$$
\begin{aligned}
\frac{\partial V^{*}(\Gamma)}{\partial \gamma}= & \left(\frac{1-\rho(\Gamma) \psi(\Gamma) \gamma}{[1-\delta(1-\rho(\Gamma))] \Omega(\Gamma)}\right) \frac{\partial p^{*}(\Gamma)}{\partial \gamma} \\
& -\left(p^{*}(\Gamma)-c\right)\left(\frac{\min \{\rho(\Gamma) \psi(\Gamma), \theta\}}{[1-\delta(1-\rho(\Gamma))](\Omega(\Gamma))^{2}}\right) .
\end{aligned}
$$

Re-arranging yields:

$$
\begin{aligned}
\frac{\partial V^{*}(\Gamma)}{\partial \gamma}= & \left(\frac{1}{[1-\delta(1-\rho(\Gamma))](\Omega(\Gamma))^{2}}\right) \times \\
& {\left[(1-\rho(\Gamma) \psi(\Gamma) \gamma) \Omega(\Gamma) \frac{\partial p^{*}(\Gamma)}{\partial \gamma}-\left(p^{*}(\Gamma)-c\right)(\min \{\rho(\Gamma) \psi(\Gamma), \theta\})\right] . }
\end{aligned}
$$

Assume a full leniency program, $\theta=0$, to simplify (16):

$$
\frac{\partial V^{*}(\Gamma)}{\partial \gamma}=\left(\frac{1-\delta(1-\rho(\Gamma))}{(1-\rho(\Gamma) \psi(\Gamma) \gamma)^{2}}\right)\left[\frac{(1-\rho(\Gamma) \psi(\Gamma) \gamma)^{2}}{1-\delta(1-\rho(\Gamma))} \frac{\partial p^{*}(\Gamma)}{\partial \gamma}\right]=\frac{\partial p^{*}(\Gamma)}{\partial \gamma}
$$


Thus, the change in collusive value with respect to $\gamma$ just equals the change in collusive price with respect to $\gamma$. By Theorem $1, \frac{\partial p^{*}(\Gamma)}{\partial \gamma}<0$ and, therefore, $\frac{\partial V^{*}(\Gamma)}{\partial \gamma}<0$, so higher penalties reduce collusive value.

What we then need to show is: if $\rho\left(\Gamma^{\prime \prime}\right) \geq \rho\left(\Gamma^{\prime}\right), \psi\left(\Gamma^{\prime \prime}\right) \geq \psi\left(\Gamma^{\prime}\right)$, and $K_{\Gamma^{\prime \prime}} \geq K_{\Gamma^{\prime}}$ (and one of them holds strictly) then $V^{*}\left(\Gamma^{\prime}\right)$ is less sensitive to $\gamma$ than is $V^{*}\left(\Gamma^{\prime \prime}\right)$ which, by (17), requires

$$
(0>) \frac{\partial p^{*}\left(\Gamma^{\prime}\right)}{\partial \gamma}>\frac{\partial p^{*}\left(\Gamma^{\prime \prime}\right)}{\partial \gamma}
$$

Total differentiating (14) with respect to $\gamma$,

$$
\frac{\partial p^{*}(\Gamma)}{\partial \gamma}=\frac{K_{\Gamma}\left[\left(\frac{\rho(\Gamma) \psi(\Gamma)}{1-\delta(1-\rho(\Gamma))}\right)-\min \{\rho(\Gamma) \psi(\Gamma), \theta\}\right]}{D^{\prime}\left(p^{*}(\Gamma)\right)\left[\left(\frac{1-\rho(\Gamma) \psi(\Gamma) \gamma}{1-\delta(1-\rho(\Gamma))}\right)+\min \{\rho(\Gamma) \psi(\Gamma), \theta\} \gamma\right]^{2}}
$$

Setting $\theta=0$,

$$
\frac{\partial p^{*}(\Gamma)}{\partial \gamma}=\frac{K_{\Gamma} \rho(\Gamma) \psi(\Gamma)(1-\delta(1-\rho(\Gamma)))}{D^{\prime}\left(p^{*}(\Gamma)\right)(1-\rho(\Gamma) \psi(\Gamma) \gamma)^{2}}
$$

Thus, $\frac{\partial p^{*}\left(\Gamma^{\prime}\right)}{\partial \gamma}>\frac{\partial p^{*}\left(\Gamma^{\prime \prime}\right)}{\partial \gamma}$ iff

$$
\begin{gathered}
\frac{K_{\Gamma^{\prime}} \rho\left(\Gamma^{\prime}\right) \psi\left(\Gamma^{\prime}\right)\left(1-\delta\left(1-\rho\left(\Gamma^{\prime}\right)\right)\right)}{D^{\prime}\left(p^{*}\left(\Gamma^{\prime}\right)\right)\left(1-\rho\left(\Gamma^{\prime}\right) \psi\left(\Gamma^{\prime}\right) \gamma\right)^{2}}>\frac{K_{\Gamma^{\prime \prime}} \rho\left(\Gamma^{\prime \prime}\right) \psi\left(\Gamma^{\prime \prime}\right)\left(1-\delta\left(1-\rho\left(\Gamma^{\prime \prime}\right)\right)\right)}{D^{\prime}\left(p^{*}\left(\Gamma^{\prime \prime}\right)\right)\left(1-\rho\left(\Gamma^{\prime \prime}\right) \psi\left(\Gamma^{\prime \prime}\right) \gamma\right)^{2}} \Rightarrow \\
\frac{K_{\Gamma^{\prime \prime}} \rho\left(\Gamma^{\prime \prime}\right) \psi\left(\Gamma^{\prime \prime}\right)\left(1-\delta\left(1-\rho\left(\Gamma^{\prime \prime}\right)\right)\right)}{\left(1-\rho\left(\Gamma^{\prime \prime}\right) \psi\left(\Gamma^{\prime \prime}\right) \gamma\right)^{2}}>\left(\frac{D^{\prime}\left(p^{*}\left(\Gamma^{\prime \prime}\right)\right)}{D^{\prime}\left(p^{*}\left(\Gamma^{\prime}\right)\right)}\right)\left(\frac{K_{\Gamma^{\prime}} \rho\left(\Gamma^{\prime}\right) \psi\left(\Gamma^{\prime}\right)\left(1-\delta\left(1-\rho\left(\Gamma^{\prime}\right)\right)\right)}{\left(1-\rho\left(\Gamma^{\prime}\right) \psi\left(\Gamma^{\prime}\right) \gamma\right)^{2}}\right)
\end{gathered}
$$

If demand is approximately linear - so $\frac{D^{\prime}\left(p^{*}\left(\Gamma^{\prime \prime}\right)\right)}{D^{\prime}\left(p^{*}\left(\Gamma^{\prime}\right)\right)} \simeq 1$ - then $(18)$ holds if

$$
K_{\Gamma^{\prime \prime}}\left[\frac{\rho\left(\Gamma^{\prime \prime}\right) \psi\left(\Gamma^{\prime \prime}\right)\left(1-\delta\left(1-\rho\left(\Gamma^{\prime \prime}\right)\right)\right)}{\left(1-\rho\left(\Gamma^{\prime \prime}\right) \psi\left(\Gamma^{\prime \prime}\right) \gamma\right)^{2}}\right]>K_{\Gamma^{\prime}}\left[\frac{\rho\left(\Gamma^{\prime}\right) \psi\left(\Gamma^{\prime}\right)\left(1-\delta\left(1-\rho\left(\Gamma^{\prime}\right)\right)\right)}{\left(1-\rho\left(\Gamma^{\prime}\right) \psi\left(\Gamma^{\prime}\right) \gamma\right)^{2}}\right]
$$

Note that $\frac{\rho \psi(1-\delta(1-\rho))}{(1-\rho \psi \gamma)^{2}}$ is increasing in $\rho$ and $\psi$. Hence, if $\rho\left(\Gamma^{\prime \prime}\right) \geq \rho\left(\Gamma^{\prime}\right), \psi\left(\Gamma^{\prime \prime}\right) \geq$ $\psi\left(\Gamma^{\prime}\right)$, and $K_{\Gamma^{\prime \prime}} \geq K_{\Gamma^{\prime}}$ (and one of them holds strictly) then (19) holds.

In sum, the introduction of a competition authority (weakly) reduces the inclusiveness of the most inclusive stable cartel. Without a competition authority, the all-inclusive cartel is the most profitable - in terms of value per unit of cartel capacity - and it is stable because cartel members can threaten to dismantle the cartel if any member leaves. However, when there is a competition authority, the most profitable cartel can be less than all-inclusive because additional members raise expected penalties and this can exceed the benefits from controlling more capacity. In particular, the most inclusive stable cartel will exclude small firms. We also find that more aggressive enforcement in terms of higher penalties cause the most profitable cartel to control less capacity and have a lower probability of paying penalties. These findings are consistent with antitrust enforcement resulting in the most inclusive cartels being less inclusive. 


\subsection{Minimal Cartel Size}

Next we turn to considering the smallest stable cartels. A cartel can be "not inclusive enough" for stability for either of two reasons. First, it may not control enough capacity to sustain any collusion; that is, the collusive price is just the static Nash equilibrium price. In that case, the cartel is not internally stable. Second, it may not be externally stable in that a non-member prefers to join because doing so sufficiently raises the collusive price and the rise in the new member's price-cost margin is enough to offset it having lower output and becoming liable for penalties. Using these two conditions, the analysis in this section shows that antitrust enforcement can either make the smallest cartels more inclusive or less inclusive.

\subsubsection{Minimal Cartel Size Rises}

The next result provides conditions whereby the smallest cartels are at least as large when there is antitrust enforcement. Specifically, when some cartels are unstable without antitrust enforcement then they are unstable with antitrust enforcement. Hence, if $\Gamma^{\prime}$ is a minimal stable cartel without an antitrust authority - which means that sub-coalitions are unstable - then those sub-coalitions are still unstable when there is an antitrust authority. If $\Gamma^{\prime}$ is still stable in an environment with antitrust enforcement then it remains a minimal stable cartel and, if it is no longer stable, then a minimal stable cartel either strictly contains $\Gamma^{\prime}$ or there is no minimal stable cartel containing $\Gamma^{\prime}$.

Theorem 8 In the absence of antitrust enforcement, assume $\Gamma^{\prime}$ is a minimal stable cartel and $p^{*}(\Gamma)=c$ for all $\Gamma \subset \Gamma^{\prime}$. Then, in the presence of antitrust enforcement, $\Gamma$ is not stable for all $\Gamma \subset \Gamma^{\prime}$.

Proof. Recall that, without antitrust enforcement, a necessary and sufficient condition for a cartel $\Gamma$ to sustain a collusive price is

$$
\frac{1}{1-\delta}>\frac{K_{\Gamma}}{D(c)-\left(K-K_{\Gamma}\right)}
$$

Hence, if

$$
\frac{1}{1-\delta} \leq \frac{K_{\Gamma}}{D(c)-\left(K-K_{\Gamma}\right)}
$$

then $p^{*}(\Gamma)=c$ and cartel $\Gamma$ is (trivially) internally unstable. As postulated for when there is no antitrust enforcement, suppose $\Gamma^{\prime}$ is a minimal stable cartel and $p^{*}(\Gamma)=c$ for all $\Gamma \subset \Gamma^{\prime}$ which means $(20)$ holds. We want to show that, in the presence of antitrust enforcement, the equivalent condition to (20) holds for all $\Gamma \subset \Gamma^{\prime}$ which means the minimal stable cartel is not a subset of $\Gamma^{\prime}$.

With antitrust enforcement, the analogue to (20) is

$$
\Omega(\Gamma) \equiv\left(\frac{1-\rho(\Gamma) \psi(\Gamma) \gamma}{1-\delta(1-\rho(\Gamma))}\right)+\min \{\rho(\Gamma) \psi(\Gamma), \theta\} \gamma \leq \frac{K_{\Gamma}}{D(c)-\left(K-K_{\Gamma}\right)}
$$


To see that (20) implies (21), note that the RHS's are the same, whereas the LHS of (21) is lower. As to the latter, if $\rho(\Gamma) \psi(\Gamma) \geq \theta$, then we need

$$
\frac{1-\gamma(\rho(\Gamma) \psi(\Gamma)-\theta)-\theta \gamma \delta(1-\rho(\Gamma))}{1-\delta(1-\rho(\Gamma))} \leq \frac{1}{1-\delta}
$$

which holds. If $\rho(\Gamma) \psi(\Gamma)<\theta$, then we need

$$
\frac{1-\delta(1-\rho(\Gamma)) \rho(\Gamma) \psi(\Gamma) \gamma}{1-\delta(1-\rho(\Gamma))} \leq \frac{1}{1-\delta},
$$

which also holds. Hence, with antitrust enforcement, $p^{*}(\Gamma)=c$ and therefore $\Gamma$ is internally unstable for all $\Gamma \subset \Gamma^{\prime}$.

In establishing that minimal stable cartel size may not fall with antitrust enforcement, the previous theorem relied on $p^{*}(\Gamma)=c$ for all sub-coalitions of the minimal stable cartel without antitrust enforcement. We'll now show that a sufficient condition for that property to hold is that market demand is sufficiently inelastic. Recall that, without an antitrust authority, $p^{*}(\Gamma)$ is defined by:

$$
p^{*}(\Gamma)=\arg \max \left(\frac{1}{1-\delta}\right)(p-c)\left[\frac{D(p)-\left(K-K_{\Gamma}\right)}{K_{\Gamma}}\right]
$$

subject to

$$
\frac{1}{1-\delta} \geq \frac{K_{\Gamma}}{D(p)-\left(K-K_{\Gamma}\right)}
$$

Assume market demand is perfectly inelastic: $D(p)=Q^{\prime}$ for $p \leq \bar{p}$ (with $\bar{p}>c$ ) and $D(p)=0$ for $p>\bar{p}$. The above problem becomes

$$
p^{*}(\Gamma)=\arg \max \left(\frac{1}{1-\delta}\right)(p-c)\left[\frac{Q^{\prime}-\left(K-K_{\Gamma}\right)}{K_{\Gamma}}\right]
$$

subject to

$$
\frac{1}{1-\delta} \geq \frac{K_{\Gamma}}{Q^{\prime}-\left(K-K_{\Gamma}\right)}
$$

which implies $p^{*}(\Gamma)=\bar{p}$ when $\frac{1}{1-\delta} \geq \frac{K_{\Gamma}}{Q^{\prime}-\left(K-K_{\Gamma}\right)}$, and $p^{*}(\Gamma)=c$ when $\frac{1}{1-\delta}<$ $\frac{K_{\Gamma}}{Q^{\prime}-\left(K-K_{\Gamma}\right)}$. Let us then show that if $p^{*}(\Gamma)=\bar{p}$ then $\Gamma$ is stable which implies: if $\Gamma^{\prime}$ is a minimal stable cartel then $p^{*}(\Gamma)=c$ for all $\Gamma \subset \Gamma^{\prime}$. If $p^{*}(\Gamma)=\bar{p}$ then firm $i \in \Gamma$ earns

$$
\left(\frac{1}{1-\delta}\right)(\bar{p}-c)\left[\frac{Q^{\prime}-\left(K-K_{\Gamma}\right)}{K_{\Gamma}}\right] k_{i}>0
$$

which implies internal stability when $W_{i}(\Gamma)=0$; that is, the aggressive equilibrium ensues if a cartel member departs because such a departure reduces the collusive 
value for the remaining cartel members. If $j \notin \Gamma$ then, even if the accommodative equilibrium ensues, it is externally stable because firm $j$ earns

$$
\left(\frac{1}{1-\delta}\right)(\bar{p}-c) k_{j}
$$

outside of the cartel and earns

$$
\left(\frac{1}{1-\delta}\right)(\bar{p}-c)\left[\frac{Q^{\prime}-\left(K-K_{\Gamma}-k_{j}\right)}{K_{\Gamma}+k_{j}}\right] k_{j}
$$

by joining the cartel which is strictly smaller. Intuitively, a firm that joins the cartel goes from producing at capacity to producing below capacity. Thus, a necessary condition for it to find it profitable to join a cartel is that, by bringing more capacity under the control of the cartel, the collusive price is higher. (Recall that both insiders and outsiders charge, approximately, the same price.) However, when market demand is perfectly inelastic, expanding the cartel does not raise the collusive price. By continuity, when market demand is sufficiently inelastic, a minimal stable cartel without a competition authority will be a least inclusive cartel that is able to sustain a collusive price, which is the condition specified in Theorem 8 .

Continuing with the case of perfectly inelastic demand, we can provide sufficient conditions for minimal cartel size to strictly expand in response to antitrust enforcement. With antitrust enforcement, the ICC with perfectly inelastic market demand takes the form:

$$
\left(\frac{1-\rho(\Gamma) \psi(\Gamma) \gamma}{1-\delta(1-\rho(\Gamma))}\right)+\min \{\rho(\Gamma) \psi(\Gamma), \theta\} \gamma \geq \frac{K_{\Gamma}}{Q^{\prime}-\left(K-K_{\Gamma}\right)}
$$

Once again, if firms are able to collude then the collusive price is $\bar{p}$. Therefore, a minimal stable cartel is a least inclusive cartel that sustains $\bar{p}$. Thus, if

$$
\frac{1}{1-\delta} \geq \frac{K_{\Gamma^{\prime}}}{Q^{\prime}-\left(K-K_{\Gamma^{\prime}}\right)}>\left(\frac{1-\rho\left(\Gamma^{\prime}\right) \psi\left(\Gamma^{\prime}\right) \gamma}{1-\delta\left(1-\rho\left(\Gamma^{\prime}\right)\right)}\right)+\min \left\{\rho\left(\Gamma^{\prime}\right) \psi\left(\Gamma^{\prime}\right), \theta\right\} \gamma
$$

then cartel $\Gamma^{\prime}$ can effectively collude in the absence of antitrust enforcement but cannot do so in the presence of antitrust enforcement. ${ }^{22}$ Therefore, minimal stable cartel size must rise in response to antitrust enforcement (at least when the expected antitrust penalty is not increasing too much in cartel size). ${ }^{23}$

${ }^{22}$ To see how (22) may hold, suppose $\theta=0$. Given that

$$
\frac{1}{1-\delta}>\left(\frac{1-\rho\left(\Gamma^{\prime}\right) \psi\left(\Gamma^{\prime}\right) \gamma}{1-\delta\left(1-\rho\left(\Gamma^{\prime}\right)\right)}\right)
$$

is true - and the RHS of the preceding inequality is the RHS of (22) when $\theta=0$ - then there exists values for $\frac{K_{\Gamma^{\prime}}}{Q^{\prime}-\left(K-K_{\Gamma^{\prime}}\right)}$ such that $(22)$ is true.

${ }^{23}$ It is possible that there does not exist a minimal stable cartel - which is surely the case if the competition policy parameters are sufficiently high - but it is easy to find intermediate values such that these inequalities hold and there still exist more inclusive cartels that are able to collude. A general set of conditions for that to be true are available. 
In sum, when market demand is sufficiently inelastic, a minimal stable cartel is the smallest cartel for which a collusive price can be sustained. By tightening the ICC, those cartels that could not sustain a collusive price, still cannot do so with antitrust enforcement. Hence, cartels cannot be less inclusive and, furthermore, may have to be more inclusive. Note that highly inelastic market demand may plausibly hold for cartels that sell an input to industrial buyers where the input makes up a small part of the cost of producing the industrial buyer's product. ${ }^{24}$ In a market with highly inelastic market demand in which the cartel is minimally inclusive, it is then predicted that antitrust enforcement would cause a cartel to make itself more inclusive in order to be able to effectively collude.

\subsubsection{Minimal Cartel Size Falls}

The next result presumes the condition in Theorem 8 does not hold. In that case, it is possible that antitrust enforcement reduces the size of a minimal stable cartel. Specifically, consider a cartel that was not externally stable in the absence of antitrust enforcement because a firm outside of the cartel found it profitable to join because it would significantly increase the collusive price. That same cartel may now be externally stable when there is antitrust enforcement. If the addition of that firm sufficiently increases the likelihood of detection then it is no longer profitable to join. As long as the cartel can still sustain a collusive price, it is also internally stable.

Theorem 9 In the absence of antitrust enforcement, assume $\Gamma^{\prime}$ is a minimal stable cartel and $p^{*}\left(\Gamma^{\prime \prime}\right)>c$ for some $\Gamma^{\prime \prime} \subset \Gamma^{\prime}$. Then, in the presence of antitrust enforcement, there exist $\rho(\cdot)$ such that $\Gamma^{\prime \prime}$ is stable; hence, it is a subset of $\Gamma^{\prime}$ that is a minimal stable cartel.

Proof. In the absence of antitrust enforcement, suppose $\Gamma^{\prime}$ is a stable cartel, $\Gamma^{\prime \prime}$ is not a stable cartel where $\Gamma^{\prime \prime} \subset \Gamma^{\prime}$, and $p^{*}\left(\Gamma^{\prime \prime}\right)>c$. Note that, in the absence of antitrust enforcement, internal stability of $\Gamma^{\prime \prime}$ is satisfied by specifying the aggressive equilibrium when a cartel member fails to join. Thus, if $\Gamma^{\prime \prime}$ is not stable, it is because it is not externally stable. Now suppose there is antitrust enforcement and let $\rho\left(\Gamma^{\prime \prime}\right)=\rho$ and $\min \left\{\rho\left(\Gamma^{\prime \prime} \cup\{j\}\right): j \notin \Gamma^{\prime \prime}\right\}=\bar{\rho}$; that is, $\bar{\rho}$ is the smallest probability of conviction that results from an outsider joining $\Gamma^{\prime \prime}$. By continuity with the case of no antitrust enforcement, if $\underline{\rho} \simeq 0$ then $\Gamma^{\prime \prime}$ is internally stable. By setting $\bar{\rho} \simeq 1, \Gamma^{\prime \prime}$ is externally stable because another firm joining the cartel is unprofitable due to the high rate of conviction making it very likely the cartel will shut down. ${ }^{25}$

An issue is what are sufficient conditions for the condition in Theorem 9 to hold. That is, one needs to show that, in the absence of antitrust enforcement, there exists

\footnotetext{
${ }^{24}$ For example, consider the lysine cartel (Connor, 2001). Lysine is used to build tissue in hogs and is a very small part of the cost of producing hogs. Thus, the price of lysine could significantly increase without much of a change in the demand for hogs and thus without much of a change in the derived market demand for lysine.

${ }^{25}$ That the penalty multiple, $\gamma$, does not matter is because cartel shutdown is forever. If instead the cartel was allowed to reform then the same theorem would be true but, in addition to $\bar{\rho} \simeq 1$, we would need $\gamma$ to be sufficiently high so that expected penalties are sufficiently high.
} 
$\Gamma^{\prime}$ such that: 1) $\Gamma^{\prime}$ is stable; 2) $\forall \Gamma \subset \Gamma^{\prime}$, $\Gamma$ is unstable (so that $\Gamma^{\prime}$ is a minimal stable cartel); and 3) $\exists \Gamma \subset \Gamma^{\prime}$ such that $p^{*}(\Gamma)>c$. There must then be cartels that are internally stable (that is, able to sustain a collusive price) but are not externally stable because a firm would want to join for the purpose of sufficiently raising price. Here we offer some sufficient conditions. Assume $\delta \simeq 1$ so that, without antitrust enforcement, the collusive price is the unconstrained price. Assuming $D(p)=1-p$, it is shown in the Appendix that cartel $\Gamma$ is internally stable (that is, $p^{*}(\Gamma)>c$ ) if and only if $K_{\Gamma}>K-1+c$, and is externally stable (that is, an outsider does not increase its profit by joining) if and only if

$$
k_{j} \leq \sqrt{K_{\Gamma}^{2}-(K-1+c)^{2}}, \forall j \notin \Gamma .
$$

Firm $j$ does not want to join if it is sufficiently small which makes sense since joining will not have much of an impact on the collusive price - given that non-cartel capacity has not fallen that much - but will have a proportionally large effect on firm $j$ 's supply. Consider cartels comprising the largest firms: $\Gamma(m) \equiv\{1, \ldots, m\}$, where recall $k_{1} \geq \cdots \geq k_{n}$. There exists cartels satisfying the property in Theorem 9 if there exists $h$ such that:

$$
k_{1}+\cdots+k_{h-1} \leq K-1+c<k_{1}+\cdots+k_{h}<\sqrt{k_{h+1}^{2}+(K-1+c)^{2}} .
$$

The first two inequalities mean that cartel $\Gamma(h)$ is the smallest cartel that is able to sustain a collusive price, and the third inequality means that the cartel is not externally stable because firm $h+1$ wants to join it.

\subsection{Discussion}

Based upon the preceding analysis, let us draw out some general insight regarding how the introduction of a competition authority affects the set of stable cartels. Recall that a cartel is stable when it is internally stable - which means firms are able to sustain a collusive price and no member earns more profit by leaving the cartel and it is externally stable - which means no outsider to the cartel would earn higher profit by joining the cartel.

External stability requires that a firm prefers not to join the cartel. Without antitrust enforcement, the rationale for joining is that it raises the collusive price - by bringing more capacity under the control of the cartel - but at the cost that the firm must then constrain its supply below capacity. With antitrust enforcement, there is an additional cost of joining which is that the firm that joins now becomes liable for penalties. Given the associated reduction in profit from becoming a cartel member, it would seem to make it more likely that any cartel satisfies external stability. Furthermore, adding a firm can raise expected penalties - by, for example, making discovery of the cartel more likely - which will lower collusive value and (weakly) lower the collusive price by tightening the ICC. Thus, price may not rise as much with the addition of this firm, compared to when there is no competition authority. As a result, cartels that were externally stable without antitrust enforcement are probably externally stable with antitrust enforcement. The impact on cartel size 
is then in terms of making previously (externally) unstable cartels now (externally) stable. Specifically, in the absence of antitrust enforcement, a relatively small cartel may have been unstable because it was externally unstable; that is, a firm wanted to join in order to expand cartel capacity and raise the collusive price. Now that there is antitrust enforcement, the prospect of becoming liable for penalties may discourage that firm from joining in which case that small cartel is now externally stable. In sum, it would seem that antitrust enforcement augments external stability - firms are less inclined to join a cartel - and this may result in smaller cartels now being stable.

Turning to internal stability, it requires, first, that the cartel has enough capacity so that a collusive price can be sustained, and, second, that the cartel value does not rise in response to a member leaving. The latter condition implies that the remaining cartel members would accommodate the exit and, given that accommodation, the exiting firm would earn more profit outside of the cartel. Based on the preceding analysis, we conjecture that the presence of a competition authority makes it less likely that a cartel will satisfy internal stability. We know that enforcement (weakly) reduces the collusive price by tightening the ICC. Thus, it could cause a cartel to lose the ability to sustain a collusive price and thus cause the cartel to be internally unstable. To successfully collude, the cartel may then need to be more inclusive in order to control more capacity (though this does depend on the rise in expected penalties from greater inclusion not being so large as to counteract that effect). Hence, antitrust enforcement may result in smaller cartels becoming larger in order to sustain a collusive price. For the most inclusive cartels, antitrust enforcement may undermine internal stability for a very different reason. A firm contributes to cartel value by having the cartel control more capacity which then allows it to raise the collusive price but, at the same time, it detracts from cartel value by increasing the probability of discovery and, more generally, raising expected penalties. Thus, antitrust enforcement could result in cartel value being enhanced by a firm leaving the cartel (which also implies the firm finds it profitable to leave) which makes the cartel internally unstable. This force means that antitrust enforcement will tend to reduce the size of large cartels. It then appears that antitrust enforcement undermines internal stability which can cause the smallest cartels to be larger and the largest cartels to be smaller. Hence, the range of stable cartels shrinks.

In sum, our analysis suggests that antitrust enforcement makes it less difficult to satisfy external stability - outsiders to a cartel are more inclined not to participate but makes it more difficult to satisfy internal stability - insiders to a cartel are more inclined not to participate. As just described, these forces make for less inclusive stable cartels. However, there is an additional way in which antitrust enforcement internally destabilizes a cartel which is that it prevents the cartel from being able to sustain a collusive price. In that case, cartel stability may require a more inclusive cartel. 


\section{Concluding Remarks}

This paper is an initial foray into how competition policy impacts the inclusiveness of cartels. We found that the presence of antitrust enforcement causes the most inclusive stable cartels to be less inclusive and, in particular, small firms that might have been cartel members in the absence of a competition authority are no longer members. Regarding the least inclusive stable cartels, the presence of antitrust enforcement can either increase or decrease their inclusiveness, depending on market conditions. When market demand is highly inelastic, it will cause the least inclusive stable cartels to encompass more firms in order to be able to sustain a collusive price.

A next step in this analysis is to examine the impact of competition policy on price when the size and composition of the cartel is endogenized. Previous research on how competition policy impacts price has presumed the cartel is all-inclusive and the all-inclusivity is unaffected by competition policy. However, competition policy can have an indirect effect on price through its impact on which firms join the cartel. Our analysis suggests that such indirect effects could be important. From a tractability perspective, conducting such an analysis will probably necessitate more structure than is assumed in this paper and may ultimately require numerical analysis.

Another potentially interesting extension of our analysis would be to allow cartels to use exclusionary tactics to restrain the supply of non-cartel members. The current analysis presumes that non-cartel members do not restrain their supply in that they price just below the cartel's price and produce up to capacity. This is obviously detrimental to the cartel and, in practice, some cartels have augmented their collusive price-setting with exclusionary activities intended to constrain the supply of non-cartel members. For example, in the district heating pipes cartel, the Swedish firm Powerpipe did not join the cartel and eventually complained to the European Commission that there was a cartel and it was acting in a predatory manner against it. ${ }^{26}$ The use of exclusionary activities also explains why non-cartel members are a common source of discovery of cartels. Hay and Kelley (1974) found that 12 out of 49 U.S. Department of Justice cases were discovered by means of a "complaint by a competitor" and was the second most common source of detection. This discussion raises two interesting issues. First, a partially inclusive cartel could be made more profitable by engaging in exclusionary activities against non-cartel members so as to reduce non-cartel supply, but doing so runs the risk of those non-cartel members complaining and the cartel being discovered. Encompassing those factors in our model could produce some new insight into both the structure of cartels and the properties of collusive practices. Second, it identifies a complementarity between competition laws. The law against price-fixing (Section 1 of the Sherman Ac in the U.S. and Article 101 TFEU in the EU) may be easier to enforce by virtue of the law against exclusionary practices (Section 2 of the Sherman Act in the U.S. and Article 102 TFEU in the EU). If some cartels are not all-inclusive - as the evidence and our analysis suggests is likely - then laws against exclusionary practices provide

\footnotetext{
${ }^{26}$ This example, and other ones, can be found in Harrington (2006) and Marshall, Marx, and Samkharadze (2011).
} 
a stronger incentive for non-cartel members to complain and a weaker incentive for cartel members to engage in such activities, which will tend to make collusion less profitable and impact the inclusiveness of cartels.

\section{Appendix: Proof of Conditions for the Property in Theorem 9 to Hold}

In Theorem 9, we have shown that antitrust enforcement may reduce minimal cartel size. A key requirement for this to occur is that, in the absence of antitrust enforcement, there exists some subset of a minimal cartel that is able to sustain a price above costs. If this requirement is not met, then we know by Theorem 8 that antitrust enforcement will not lead to smaller minimal cartels. This raises the issue of when without antitrust enforcement there exists a cartel $\Gamma$ such that: 1) $\Gamma$ is stable, 2) $\Gamma^{\prime}$ is unstable for all $\Gamma^{\prime} \subset \Gamma$ and 3) there exists a cartel $\Gamma^{\prime} \subset \Gamma$ for which $p^{*}\left(\Gamma^{\prime}\right)>c$. In the following, we present sufficient conditions for this property to hold.

- Step 1: Derive conditions under which a cartel $\Gamma$ is stable.

To begin, assume that $D(p)=1-p$ and $\delta \simeq 1$. Thus, for a given cartel $\Gamma$, the ICC is not binding. In this case, the optimal cartel price is given by

$$
p^{*}(\Gamma)=\frac{1-K+K_{\Gamma}+c}{2} .
$$

For $\Gamma$ to be internally stable through the aggressive equilibrium it must hold that $p^{*}(\Gamma)>c$, which requires

$$
K_{\Gamma}>\frac{K-D(c)}{\delta} \simeq K-1+c .
$$

This cartel is externally stable when none of the outsiders finds it profitable to join, which is the case when

$$
\left(\frac{1}{1-\delta}\right)\left[p^{*}(\Gamma)-c\right] k_{j} \geq\left(\frac{1}{1-\delta}\right)\left[p^{*}(\Gamma \cup\{j\})-c\right]\left(\frac{1-p^{*}(\Gamma \cup\{j\})-\left(K-K_{\Gamma}-k_{j}\right)}{K_{\Gamma}+k_{j}}\right) k_{j}, \forall j \notin \Gamma,
$$

or

$$
p^{*}(\Gamma)-c \geq\left[p^{*}(\Gamma \cup\{j\})-c\right]\left(\frac{1-p^{*}(\Gamma \cup\{j\})-\left(K-K_{\Gamma}-k_{j}\right)}{K_{\Gamma}+k_{j}}\right), \forall j \notin \Gamma .
$$

By using

$$
p^{*}(\Gamma \cup\{j\})=\frac{1-K+K_{\Gamma}+k_{j}+c}{2},
$$

the external stability condition reduces to 


$$
\left(K_{\Gamma}+k_{j}\right)\left[p^{*}(\Gamma)-c\right] \geq\left(p^{*}(\Gamma \cup\{j\})-c\right)^{2}, \forall j \notin \Gamma .
$$

Substituting $p^{*}(\Gamma)=\frac{1-K+K_{\Gamma}+c}{2}$ and $p^{*}(\Gamma \cup\{j\})=\frac{1-K+K_{\Gamma}+k_{j}+c}{2}$ and rearranging gives

$$
K_{\Gamma} \geq \sqrt{k_{j}^{2}+(K-1+c)^{2}} \Leftrightarrow \sqrt{K_{\Gamma}^{2}-(K-1+c)^{2}} \geq k_{j}, \forall j \notin \Gamma,
$$

which implies $K_{\Gamma}>K-1+c$. We therefore conclude that a cartel $\Gamma$ is stable when the following condition holds:

$$
K_{\Gamma} \geq \sqrt{k_{j}^{2}+(K-1+c)^{2}}, \forall j \notin \Gamma .
$$

\section{- Step 2: Derive conditions under which the cartel is minimally stable.}

Let us now show when $\Gamma^{\prime}$ is unstable for all $\Gamma^{\prime} \subset \Gamma$. Towards that end, consider cartels that involve the largest firms: $\Gamma(m) \equiv\{1, \ldots, m\}$ and define $h$ by

$$
k_{1}+\cdots+k_{h-1} \leq K-1+c<k_{1}+\cdots+k_{h} .
$$

Thus, $p^{*}(\Gamma(h))>c$ and $p^{*}(\Gamma(m))=c, \forall m<h$. Cartel $\Gamma(h)$ is therefore the smallest cartel for which a price above cost is sustainable. Observe that there always exists a $h$ for which this condition is satisfied since for $h=2$ we have $k_{1} \leq K-1+c$, which holds by assumption and for $h=n$ we have $K-1+c<k_{1}+\cdots+k_{n} \Leftrightarrow 1-c>0$, which again holds by assumption.

Next, suppose there exists $r$ satisfying:

$$
k_{1}+\cdots+k_{r-1}<\sqrt{k_{r}^{2}+(K-1+c)^{2}},
$$

and

$$
\sqrt{k_{r+1}^{2}+(K-1+c)^{2}} \leq k_{1}+\cdots+k_{r} .
$$

We show below that such an $r$ exists and is unique. Now consider a cartel $\Gamma(m)$ for which $m<r$. Such a cartel is unstable because: 1) If $m \in\{h, \ldots, r-1\}$, then it is internally stable through the aggressive equilibrium, but externally unstable as firm $m+1$ wants to join; and 2) If $m \in\{2, \ldots, h-1\}$, then it is internally unstable as $p^{*}(\Gamma(m))=c$. By contrast, the cartel $\Gamma(r)$ is stable because: 1$)$ it is internally stable since $k_{1}+\cdots+k_{r} \geq \sqrt{k_{r+1}^{2}+(K-1+c)^{2}}$ implies $k_{1}+\cdots+k_{r}>K-1+c$ and thus $p^{*}(\Gamma(r))>c$; and 2) it is externally stable because firm $r+1$ prefers not to join. In turn, this implies that firm $s$ prefers not to join $\forall s>r+1$. That is, if firm $r+1$ does not want to join the cartel containing the $r$ largest firms, then all smaller firms do not want to join either.

As a final step, let us show that $\Gamma(r)$ is not only stable, but also minimally stable. We know that

$$
k_{1}+\cdots+k_{r-1}<\sqrt{k_{r}^{2}+(K-1+c)^{2}} .
$$


So, the cartel $\Gamma(r-1)$ is not externally stable. Next consider any $\Gamma \subset \Gamma(r)$. If $p^{*}(\Gamma)=c$, then $\Gamma$ is not internally stable. If $p^{*}(\Gamma)>c$, then it is internally stable, but not externally stable because

$$
k_{1}+\cdots+k_{r-1}<\sqrt{k_{r}^{2}+(K-1+c)^{2}}
$$

implies

$$
\sum_{j \in \Gamma} k_{j}<\sqrt{k_{i}^{2}+(K-1+c)^{2}} \text { for } i \notin \Gamma \text { and } i \leq r .
$$

This is true, because $k_{1}+\cdots+k_{r-1} \geq \sum_{j \in \Gamma} k_{j}$. Therefore, the LHS of (24) is smaller than the LHS of (23) and the RHS of (24) is weakly larger than the RHS of (23). Hence, firm $i \notin \Gamma$ would choose to join $\Gamma$, which means that all $\Gamma \subset \Gamma(r)$ are unstable. The cartel $\Gamma(r)$ is therefore not only stable, but also minimally stable.

\section{- Step 3: Derive conditions under which a subset of $\Gamma(r)$ can sustain a collusive price.}

What remains is to find $m$ such that $r>m \geq h$. That is, there are subsets of the minimal stable cartel $\Gamma(r)$ that have sufficient capacity to support a collusive price. For such a subset it must hold that

$$
K-1+c<k_{1}+\cdots+k_{m}<\sqrt{k_{m+1}^{2}+(K-1+c)^{2}} .
$$

Note that if this condition is not satisfied for $m=h$, so that

$$
\sqrt{k_{h+1}^{2}+(K-1+c)^{2}} \leq k_{1}+\cdots+k_{h},
$$

then it does not hold for any $m>h$ (as the RHS is increasing in $m$ and the LHS is non-increasing in $m$ ). Thus, the necessary and sufficient condition is that $\exists h$ such that:

$$
k_{1}+\cdots+k_{h-1} \leq K-1+c<k_{1}+\cdots+k_{h}<\sqrt{k_{h+1}^{2}+(K-1+c)^{2}} .
$$

This means that the smallest cartel that is able to sustain a collusive price (cartel $\Gamma(h))$ needs to be externally unstable.

To conclude, let us show that $r$ exists and is unique. Define $r$ by

$$
\phi(r-1)<0 \leq \phi(r)
$$

and let

$$
\phi(m) \equiv k_{1}+\cdots+k_{m}-\sqrt{k_{m+1}^{2}+(K-1+c)^{2}} .
$$

Note that $\phi(m)$ is strictly increasing in $m$. Hence, if $\phi(1)<0<\phi(n)$, then there exists a unique $r$ such that: $\phi(r-1)<0 \leq \phi(r)$. For $\phi(1)<0$, it must hold that

$$
k_{1}-\sqrt{k_{2}^{2}+(K-1+c)^{2}}<0 .
$$


This inequality is satisfied when

$$
\sqrt{(K-1+c)^{2}}>k_{1} \Leftrightarrow K-k_{1}>1-c,
$$

which is true by assumption. For $\phi(n)>0$, it must hold that

$$
K-\sqrt{(K-1+c)^{2}}>0 \Leftrightarrow 1-c>0,
$$

which too holds by assumption. Thus, there exists a unique $r$ such that $\phi(r-1)<$ $0 \leq \phi(r)$.

\section{References}

[1] d'Aspremont, Claude, Alexis Jacquemin, Jean Jaskold Gabszewicz, and John A. Weymark, "On the Stability of Collusive Price Leadership," Canadian Journal of Economics, 16 (1983), 17-25.

[2] Bos, Iwan and Joseph E. Harrington, Jr., "Endogenous Cartel Formation with Heterogeneous Firms," RAND Journal of Economics, 41, (2010), 92-117.

[3] Connor, John M., "Global Price Fixing: Our Customers are the Enemy," Boston: Kluwer Academic Publishers, (2001).

[4] Diamantoudi, Effrosyni, "Stable cartels revisited," Economic Theory, 26 (2005), 907-921.

[5] Donsimoni, Marie-Paule, "Stable Heterogeneous Cartels," International Journal of Industrial Organization, 3 (1985), 451-467.

[6] Donsimoni, Marie-Paule, Nicholas Economides, and Heracles Polemarchakis, "Stable Cartels," International Economic Review, 27 (1986), 317-327.

[7] Harrington, Joseph E., Jr. "Cartel Pricing Dynamics in the Presence of an Antitrust Authority," RAND Journal of Economics, 35 (2004), 651-673.

[8] Harrington, Joseph E., Jr. "Optimal Cartel Pricing in the Presence of an Antitrust Authority," International Economic Review, 46 (2005), 145-169.

[9] Harrington, Joseph E. Jr., "How Do Cartels Operate?," Foundations and Trends in Microeconomics, 2 (2006), Issue \#1.

[10] Harrington, Joseph E., Jr., "Optimal Corporate Leniency Programs," Journal of Industrial Economics, 56 (2008), 215-246.

[11] Harrington, Joseph E., Jr. and Myong-Hun Chang, "Endogenous Antitrust Enforcement in the Presence of a Corporate Leniency Program," University of Pennsylvania, October 2012. 
[12] Hay, George A. and Daniel Kelly, "An Empirical Survey of Price Fixing Conspiracies," Journal of Law and Economics, 17 (1974), 13-38.

[13] Marshall, Robert C., Leslie M. Marx and Lily Samkharadze, "Dominant-Firm Conduct by Cartels," Penn State University, February 2011.

[14] Spagnolo, Giancarlo, "Leniency and Whistleblowers in Antitrust," in Handbook of Antitrust Economics, Paolo Buccirossi, ed., Cambridge, Mass.: The MIT Press, 2008. 